\title{
The effects of immigration on NHS waiting times ${ }^{\text {is }}$
}

\author{
Osea Giuntella ${ }^{\mathrm{a}, *}$, Catia Nicodemo $^{\mathrm{b}}$, , Carlos Vargas-Silva $^{\mathrm{c}}$ \\ a University of Pittsburgh, IZA, Department of Economics, Posvar Hall, 230 S Bouquet St, Pittsburgh, PA 15260, USA \\ ${ }^{\mathrm{b}}$ University of Oxford, CHSEO, IZA, Department of Economics, Manor Road, OX13UQ Oxford, Oxfordshire, UK \\ c University of Oxford, Centre on Migration, Policy and Society (COMPAS), 58 Banbury Rd, OX26QS Oxford, Oxfordshire, UK
}

\section{A R T I C L E I N F O}

\section{Article history:}

Received 8 March 2017

Received in revised form 19 January 2018

Accepted 1 February 2018

Available online 10 February 2018

\section{JEL classification:}

J61

I10

\section{Keywords:}

Immigration

Waiting times

NHS

Access to health care

Welfare

\begin{abstract}
A B S T R A C T
This paper analyzes the effects of immigration on waiting times for the National Health Service (NHS) in England. Linking administrative records from Hospital Episode Statistics (2003-2012) with immigration data drawn from the UK Labour Force Survey, we find that immigration reduced waiting times for outpatient referrals and did not have significant effects on waiting times in accident and emergency departments (A\&E) and elective care. The reduction in outpatient waiting times can be explained by the fact that immigration increases natives' internal mobility and that immigrants tend to be healthier than natives who move to different areas. Finally, we find evidence that immigration increased waiting times for outpatient referrals in more deprived areas outside of London. The increase in average waiting times in more deprived areas is concentrated in the years immediately following the 2004 EU enlargement and disappears in the medium term (e.g., 3-4 years).
\end{abstract}

(c) 2018 The Authors. Published by Elsevier B.V. This is an open access article under the CC BY-NC-ND license (http://creativecommons.org/licenses/by-nc-nd/4.0/).

\section{Introduction}

The impact of immigration on the welfare of host-country residents has long been a contentious topic. In the UK, a majority of the public has been opposed to more immigration since at least the 1960s, and most people perceive the costs of immigration to be greater than the benefits (Blinder, 2012). The EU enlargement of May 1, 2004, exacerbated this debate as citizens of eight new member states (Czech Republic, Estonia, Hungary, Latvia, Lithua-

\footnotetext{
is This paper benefited from discussion with Christian Dustmann, Francesco Fasani, Jesus Fernandez-Huertas Moraga, Tommaso Frattini, Martin Gaynor, Hugh Gravelle, Barry McCormick, Giuseppe Moscelli, Giovanni Peri, Stuart Redding, Alessandro Tarozzi, Jonathan Wadsworth, Judit Vall-Castello, Raphael Wittenberg. We thank participants to seminars at Universitat de Barcelona, Carnegie Mellon University, King's College, University of Munich, Universitat Pompeu Fabra, University of Oxford, Royal Economic Society Conference (2015), International Health Economics Association Conference (2015), XIII IZA Annual Migration Conference. We thank Yvonni Markaki for precious research assistance. The scoping research for this paper was funded by the John Fell Oxford University Press (OUP) Research Fund and the main research was funded by the European Union Horizon 2020 research and innovation programme under grant agreement no 727072 (REMINDER Project).

* Corresponding author.

E-mail addresses: osea.giuntella@pitt.edu (O. Giuntella), catia.nicodemo@economics.ox.ac.uk (C. Nicodemo), carlos.vargas-silva@compas.ox.ac.uk (C. Vargas-Silva).
}

nia, Poland, Slovakia and Slovenia), commonly referred to as the A8, were granted immediate unrestricted rights to work in the country. The UK was one of only three EU countries, including Ireland and Sweden, that opened its labor market to A8 citizens immediately upon accession, a decision that led to a substantial immigrant inflow to the UK.

Previous papers have analyzed the effect of immigration in the UK on public finances (Dustmann et al., 2010; Dustmann and Frattini, 2014), labor markets (Dustmann et al., 2013), the housing market (Sá, 2015) and crime (Bell et al., 2013), among others. We know less about the effects of immigration on the National Health Service (NHS). Residents of the UK, including immigrants, have free access to the NHS. This free access has resulted in speculation that immigrants may increase the demand for NHS services disproportionately and that some immigrants move to the UK with the explicit purpose of abusing the health care system. These arguments and the potential health care costs associated with immigration have resulted in the introduction of an NHS surcharge for non-EU citizens applying for a UK visa.

Despite the intense political debate on the impact of immigration on the NHS, research on this topic has been limited by the paucity of data. Using longitudinal data from the British Household Panel Survey, Wadsworth (2013) finds that immigrants generally use hospital and general practice services at the same rate as those born in the UK. Steventon and Bardsley (2011) provide evidence 
suggesting that the belief that immigrants use more secondary care than British natives may be unfounded. Although these are valuable findings, these studies do not provide information on the impact of immigration on NHS efficiency. Waiting times are an important measure of the quality and productivity of a public health care system (Castelli et al., 2007; Gaynor et al., 2012a; Propper et al., 2008a). This paper aims to provide insights on this impact by examining NHS waiting times.

Waiting times function as a rationing mechanism in the NHS and play a role similar to a price (Lindsay and Feigenbaum, 1984). Research suggests that waiting times are one of the leading factors of patients' dissatisfaction with the NHS (Appleby, 2012; Sitzia and Wood, 1997; Propper, 1995). Postponing treatment delays the associated benefits and can have negative effects on patient health (Siciliani and Iversen, 2012; Cullis et al., 2000). Average waiting times for some NHS services were considerably high during the 2000s, and British politicians have suggested that increased immigration was a key factor contributing to NHS waiting times.

Between 1993 and 2013, the number of foreign-born UK residents more than doubled from 3.8 million to approximately 7.8 million (Rienzo and Vargas-Silva, 2012). This increase in the stock of immigrants is likely to have directly increased the demand for health care services. Immigration also affects the demographic composition and population morbidity rates, two factors that have key repercussions for health care demand. These effects of immigration are likely to vary significantly by location, as there is substantial variation across local areas in both the share of immigrants and NHS capacity.

Using a basic theoretical framework, this paper investigates the effects of immigration on waiting times in the NHS. We consider waiting times in outpatients (referrals), elective care (inpatients) and $A \& E .{ }^{1}$ We exploit a unique dataset created by merging administrative records and survey data. To the best of our knowledge, no studies have directly examined the impact of immigration on NHS waiting times. The purpose of this paper is to fill this gap in the literature.

Following previous studies on the effects of immigration in the UK (Sá, 2015; Bell et al., 2013), we analyze the correlation between spatial variation in the immigrant inflows and waiting times in England. We use immigration data at the local authority level drawn from the special license access version of the UK Labour Force Survey (LFS), obtained via an agreement with the Office of National Statistics (ONS). To study the effects of immigration on waiting times in the NHS, we merge this information with administrative records drawn from the Hospital Episodes Statistics (HES) provided by the Health and Social Care Information Centre (HSCIC) and extracted at the lower super output area (LSOA) level.

As waiting times are not based on socioeconomic status, they are usually viewed as an equitable rationing mechanism in publicly funded health care systems. However, research provides evidence of marked inequalities in waiting times across socioeconomic status (Cooper et al., 2009; Laudicella et al., 2012; Barr et al., 2014; Propper et al., 2007). Thus, we also analyze differences in our results based on the level of deprivation of the LSOA in order to explore differences in the impact of immigration in different areas.

To address the concern that immigration may be endogenous to the demand for health services and correlated with unobserved determinants of NHS waiting times, we use popular instrumental

\footnotetext{
1 The patient journey usually begins in primary care and can begin with a diagnostic procedure (outpatients), before entering the secondary care system for either an opinion, diagnosis, treatment or procedure. Outpatients are patients who are not hospitalized overnight but who visit a hospital, clinic, or associated facility for diagnosis or treatment. Elective care is planned care. An elective procedure is one that is advantageous to the patient but it is not urgent.
}

variable approach which exploits the fact that historical concentrations of immigrants are a good predictor of current immigrant inflows. By including local-area and year fixed effects and controlling for local time-varying characteristics, we can reasonably assume that past immigrant concentrations are uncorrelated with current unobserved shocks that could be correlated with demand for health care services.

Although the political debate has mostly focused on the possible effects of immigration on A\&E, we find no evidence of significant effects on waiting times in A\&E. While the coefficient is positive, the point-estimate is small and not precisely estimated. However, it is important to note that we only have information on $A \& E$ waiting times for the 2007-2012 period. On the other hand, using 2003-2012 data, we find a reduction in waiting times for outpatient care. In particular, we show that an increase in the stock of immigrants equal to $10 \%$ of the local initial population leads to a $19 \%$ reduction in outpatient waiting times. Finally, immigration is positively associated with inpatient waiting times for the 2003-2012 period, but the effects are smaller in absolute value (+2\%) and notprecisely estimated.

To investigate the mechanisms underlying the negative effect of immigration on waiting times, we analyze the effects of immigration on native mobility, average morbidity in the population and health care supply. Consistent with previous studies, our results indicate that immigration increases natives' likelihood of moving to different local authorities. The analysis also confirms that recent cohorts of immigrants are relatively young and healthy upon arrival ("healthy immigrant effect"), suggesting that the increase in demand may have been less than predicted by the NHS (Sá, 2015; Wadsworth, 2013; Steventon and Bardsley, 2011). These effects on mobility and population composition are likely to explain some of the observed reduction in waiting times. Meanwhile, the results suggest that the supply of health care is not affected by immigration.

Finally, we find that waiting times increased in areas that native internal migrants moved into - with respect to areas that received more immigrants - and that immigration increased the average waiting time for outpatients living in deprived areas outside of London in the period immediately following the 2004 EU enlargement. Our findings suggest that the short-term increase in outpatient waiting times in deprived areas in response to immigration can be explained by both the lower mobility of incumbent residents in these areas and the higher morbidity observed among immigrants moving into more deprived areas.

This paper is organized as follows. Section 2 presents the theoretical framework. Section 3 provides a discussion of the empirical specification, the identification strategy and the data. Section 4 presents the main results of the paper and a battery of robustness checks. Section 5 discusses the potential mechanisms explaining the main findings. We then illustrate the heterogeneity of the results across England in Section 6. Concluding remarks are given in Section 7.

\section{Theoretical framework}

We illustrate the relationship between immigration and waiting times using a basic model of the demand and supply of health care services. Our model builds on Lindsay and Feigenbaum (1984), Windmeijer et al. (2005), Martin et al. (2007), Siciliani and Iversen (2012), and we extend the model to explicitly incorporate the effects of immigration. Unless admitted through A\&E, all patients are referred by their GP to access NHS care. If patients receive a referral, they join the waiting list for outpatient care. The specialist can decide whether the patient needs elective hospital care, in which case the patient is placed on the waiting list for hospital admission. 
Following Siciliani and Iversen (2012), we can describe the demand and supply function in the following way:

$Y_{i}^{d}=\alpha_{0}+\alpha_{1} w_{i}+\alpha_{2} x_{i}^{d}+\alpha_{3} z_{i}+e_{i}^{d}$

$Y_{i}^{s}=\beta_{0}+\beta_{1} w_{i}+\beta_{2} X_{i}^{s}+\beta_{3} z_{i}+e_{i}^{s}$

where $Y_{i}^{d}$ and $Y_{i}^{S}$ are the demand and supply of health care in area $i, w_{i}$ is the waiting time, $z_{i}$ are demand or supply shifters. Under the equilibrium assumption $Y_{i}^{d}=Y_{i}^{S}$, we can write the waiting time as a function of demand and supply shifters:

$w_{i}=\gamma_{0}+\gamma_{1} x_{i}^{d}+\gamma_{2} x_{i}^{s}+\gamma_{3} z_{i}+e_{i}$

where

$\gamma_{0}=\frac{\alpha_{0}-\beta_{0}}{\beta_{1}-\alpha_{1}}, \quad \gamma_{1}=\frac{\alpha_{2}}{\beta_{1}-\alpha_{1}}, \quad \gamma_{2}=\frac{-\beta_{2}}{\beta_{1}-\alpha_{1}}, \quad \gamma_{3}=\frac{\alpha_{3}-\beta_{3}}{\beta_{1}-\alpha_{1}}$

We can adapt this framework to analyze the effects of immigration as an exogenous shock to the demand for health care services. Formally,

$w_{i t}=\lambda_{0}+\lambda_{1} I M M_{i t}+\lambda_{2} X_{d, i t}+\lambda_{3} X_{s, i t}+\lambda_{4} Z_{i t}+\mu_{i}+\eta_{t}+e_{i t}$

where $w_{i t}$ is the average waiting time in local area $i, \lambda_{1}$ captures the effect of an increase in the number of immigrants living in local area $i$ on waiting times, $\lambda_{2}\left(\lambda_{3}\right)$ are the parameters associated with a vector of variables controlling for other demand (supply) shifters, $\lambda_{4}$ captures the effects of variables affecting both the supply and demand for health care services, and $\mu_{i}$ and $\eta_{t}$ are the health local area and time fixed effects. It is worth noting that while this simple conceptual framework highlights the potential channels through which immigration may affect waiting times, it is not meant to explain the relationship between waiting times for an outpatient consultation and the waiting time for an elective treatment.

Patients can alternatively seek private care or receive no care at all if the waiting time becomes too long. The demand for NHS care will depend on the expected waiting time and on various demand shifters, such the health needs of the population (e.g., morbidity), the proportion of elderly patients, the overall size of the population, and other variables that may affect both the supply and demand of health care services (e.g., the quality of NHS care, the level of competition).

The sign of the effect of immigration on waiting times $\left(\lambda_{1}\right)$ is ambiguous. An increase in the number of immigrants will affect demand and supply through its effects on demand shifters $\left(X_{d, i t}\right)$, patients' and managers' expected waiting time, and the supply of health care personnel. The effect on waiting times $\left(\lambda_{1}\right)$ will tend to be positive if the increase in the immigrant population is not offset by an increase in the supply. In the short term, managers may be constrained by the annual budget-setting process. Moreover, as managers forecast waiting times depend on the predicted change in population based on previous observations, unexpected immigration inflows may result in excess demand. As such, the supply may not adjust immediately because of differences between predicted and actual inflows or because of budget constraints. By contrast, the effect could be negative if the supply increases more than the actual demand for health care services. This may occur if immigration leads natives to move to and/or seek care in different areas or in the private sector and if immigrants have a lower incidence of morbidities or, more generally, a lower demand for health care services. If natives with higher incomes are more likely to move (or seek private care) as a response to immigration inflows, one may expect the negative effect of native out-migration on waiting times to be amplified in less deprived areas. One may instead expect larger positive effects of immigration on waiting times in areas where the demand for health care services is less elastic (higher mobility costs) or in areas that attract less healthy immigrants.

\section{Data and empirical specification}

\subsection{Data}

Data on waiting times are extracted from the HES database provided by the HSCIC. This database includes patients treated by the publicly funded NHS in England. The HES database is a record-based system that covers all NHS trusts in England, including acute hospitals, primary care trusts and mental health trusts and Independent Sector Treatment Centres (ISTCs). ${ }^{2}$

We extracted data on waiting times and basic population demographics from the HES at the LSOA level. LSOAs were designed to improve the reporting of small-area statistics and are constructed from groups of output areas. England is divided into 32,483 LSOAs with a minimum population of 1000 inhabitants and a maximum of 3000 inhabitants.

The HES dataset provides counts and time waited for all patients referred or admitted to a hospital (inpatients, outpatients and A\&E). For outpatients and inpatients, we restrict the analysis to first admissions. ${ }^{3}$ Data on waiting times for outpatients and elective care are available for the entire period under analysis (2003-2012), while we have data on A\&E only since 2007. Waiting times for outpatients are defined as the number of days that a patient waits from the referral date to the appointment with the specialist; waiting times for elective care are defined as the period between the date of the decision to admit and the date of actual admission. For the A\&E department, waiting times are defined as the minutes from a patient's arrival in the A\&E room and the decision to transfer, admit or discharge the patient. We calculate the average waiting time for outpatients, elective care and A\&E by the LSOA of patients' residence. Note that in England, to access an NHS specialist, individuals must obtain a referral from their GP. Until 2015, although patients had the right to choose a GP practice, for most people, this choice was limited to a practice near where they lived, as the GP surgeries could refuse to register patients who resided outside the practice boundaries. ${ }^{4}$ Until 2006, patients had no choice in their hospital when seeking a referral to see a specialist; the GP would decide for the patient. Since January 2006, NHS patients can choose between 5 hospitals. However, the evidence suggests that patients have strong preferences for short distances and that, on average, patients did not travel any farther and were as likely to choose the closest hospital after the 2006 reform (Gutacker et al., 2015; Gaynor et al., 2012). As noted by Dixon and Robertson (2011), despite the increased choice and the provision of information on differences in the quality of care between hospitals, patients tend to be loyal to their local providers. For instance, Beckert et al. (2012) show that, on average, patients traveled just over $12 \mathrm{~km}$ for a hip operation in 2008-2009. One drawback of using administrative records from the HES dataset is that we cannot distinguish patients based on the country of birth. Thus, we are not able to distinguish whether the effects of immigration are different for natives and immigrants.

In addition, we use data at the primary care trust (PCT) level from the HES and HSCIC databases on the supply side, including information on the number of GPs, the number of GP practices, the number of specialists, the ratio of occupied beds in the PCT hospitals, the annual NHS expenditure and the number of doctors with a foreign degree. Using these variables, we can partially account for time-varying changes in the NHS supply at the PCT level. PCTs

\footnotetext{
2 ISTCs provide services to NHS patients but are owned and run by organizations outside the NHS. They were introduced in England in 2003, primarily to help the NHS reduce waiting times for planned operations and diagnostic tests.

3 We exclude data on delivery from the analysis.

4 Since January 5, 2015, all GP practices in England are free to register new patients who live outside their practice boundary area. See also http://www.nhs. uk/choiceintheNHS/Yourchoices/GPchoice/Pages/ChoosingaGP.aspx.
} 


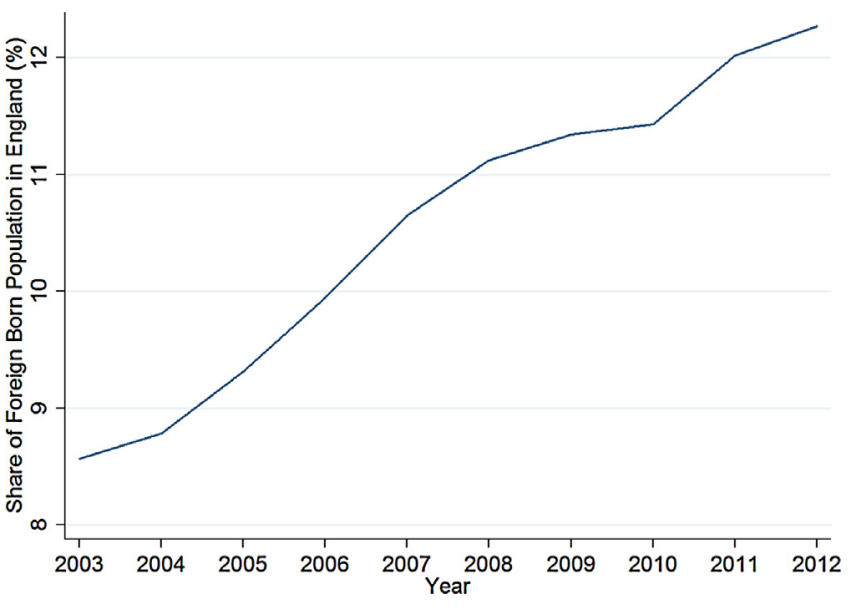

Fig. 1. Foreign-born share of the population in England. Notes - Data are drawn from the UK Labor Force Survey (2003-2012).

were largely administrative bodies responsible for commissioning primary, community and secondary health services from providers until 2013. As of October 1, 2006, there were 152 PCTs in England, with an average population of just under 330,000 per trust. PCTs were replaced by clinical commissioning groups on March 31,2013, as part of the Health and Social Care Act of 2012. Our control variables are all extracted at the LSOA or PCT level depending on their availability. $^{5}$

We use information on the immigrant population by local authority and year drawn from the special license of the UK LFS between 2003 and 2012. We define immigration based on country of birth and pool quarters for each year. The LFS is the largest household survey in the UK and consists of a sample of approximately 40,000 households (100,000 individuals) per quarter. Even with its large size, concerns could arise regarding the accuracy with which this survey measures the size of the immigrant stock at smaller geographical levels (even when data are pooled across quarters for a given year). Therefore, as a robustness check, we also use data from NINO registrations of overseas nationals from the Department for Work and Pensions (see Section 4.4 and the Data Appendix).

The merged sample includes 32,483 LSOAs, 141 local authorities, 150 PCTs, and 16 regions of residence in England. Each LSOA belongs to a given PCT and a given local authority. In our sample, 127 PCTs (90\%) are coterminous with local authorities.

Table 1 presents the summary statistics on waiting times, the immigrant share of the population and a vector of variables affecting the demand and supply of health care services. For the 2003-2012 period, the average waiting time for outpatients was 47 days, while that for inpatients was 70 days. The average waiting time for A\&E was 52 min.

The native population of the UK has remained relatively stable for the last decade. In contrast, the foreign-born population increased continuously over the same period, with a sharp increase in individuals born in other EU countries. Fig. 1 shows the growth in the foreign-born share of the population of England between 2003 and 2012. During that period, the foreign-born share of the

\footnotetext{
5 The allocation of fudging at PCT level, (CCG level after 2012), is based on age, gender, deprivation, morbidity, and population size. Thus, population mobility has the potential of changing the available funding at PCT level. Unfortunately, we do not have any data on the allocation resource at PCT level. However, in all our estimations, we control for the size of the population, the index of deprivation, the prevalence diseases (trough the QoF), the gender and the age of the population in each PCT. Furthermore, the allocation formula is based on ONS population projections and GP registrants lists which do not always reflect reality (e.g., new immigrants not registering with GPs, unexpected internal movements).
}

Table 1

Summary statistics, 2003-2012.

\begin{tabular}{|c|c|c|}
\hline & Mean & Std \\
\hline \multicolumn{3}{|l|}{ Waiting times (LSOA-level, Source: NHS, HES) } \\
\hline Waiting time for outpatients (days) & 47.06 & $(16.61)$ \\
\hline Waiting time for elective (days) & 69.82 & $(39.51)$ \\
\hline Waiting time for A\&E ( $\mathrm{min})$ & 51.98 & $(64.56)$ \\
\hline \multicolumn{3}{|l|}{ LSOA characteristics } \\
\hline Log total population & 7.35 & $(0.15)$ \\
\hline Share of women over 60 & 0.12 & $(0.05)$ \\
\hline Share of men over 65 & 0.07 & $(0.03)$ \\
\hline Share of women & 0.51 & $(0.03)$ \\
\hline Rural index (1-8) & 5.30 & $(0.86)$ \\
\hline IMD score & 21.54 & $(15.61)$ \\
\hline \multicolumn{3}{|l|}{ Supply characteristics (PCT-level, Source: NHS, ONS) } \\
\hline GPs per $1 \mathrm{k}$ pop & 0.94 & $(0.17)$ \\
\hline Specialists per $1 \mathrm{k}$ pop & 0.16 & $(0.03)$ \\
\hline Ratio of occupied hospital beds to population & 0.82 & $(0.19)$ \\
\hline NHS expenditure per capita, (000s) & 1.11 & $(0.59)$ \\
\hline \multicolumn{3}{|c|}{ Incidence of disease (PCT-level, per 1000, Source: HES, ONS) } \\
\hline Stroke & 16.61 & $(3.88)$ \\
\hline Coronary disease & 37.28 & $(8.57)$ \\
\hline Hypertension & 138.25 & $(18.60)$ \\
\hline Diabetes & 39.14 & $(7.11)$ \\
\hline Pulmonary disease & 15.19 & $(4.80)$ \\
\hline Epilepsy & 6.32 & $(1.04)$ \\
\hline Hypothyroidism & 26.60 & $(6.20)$ \\
\hline Cancer & 9.43 & $(4.17)$ \\
\hline Mental health & 7.00 & $(2.13)$ \\
\hline Ventricular disfunction & 5.30 & $(0.86)$ \\
\hline \multicolumn{3}{|l|}{ Immigration (LA-level, Source: LFS) } \\
\hline Share of immigrants (LFS) & 11.75 & $(10.99)$ \\
\hline Observation & 287,092 & 287,092 \\
\hline
\end{tabular}

Notes - Data are drawn from the Hospital Episodes Statistics, the UK Labor Force Survey, and the UK ONS.

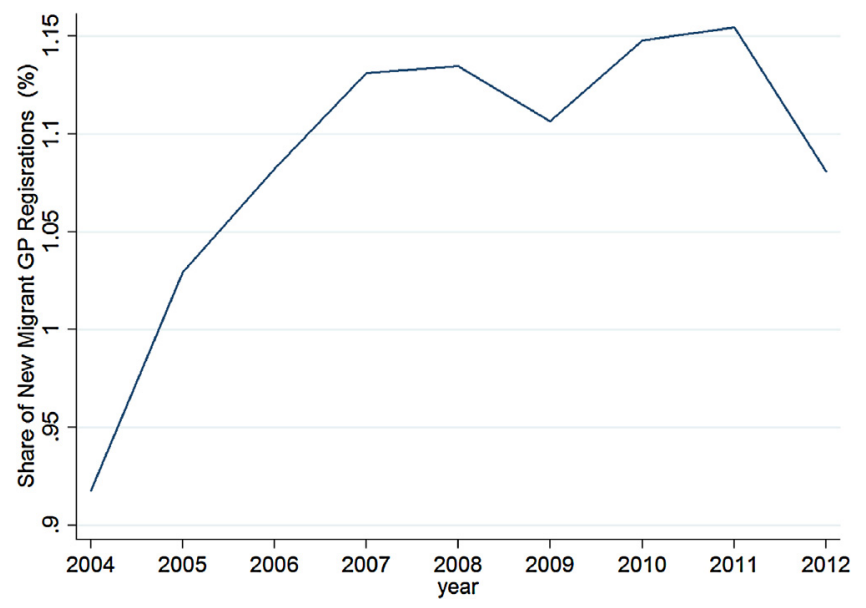

Fig. 2. Annual number of new immigrant registrations with a GP as share of total population. Notes - Source: Patient Register Data Service (2004-2012).

working-age population increased from $9 \%$ to $13 \%$. The EU expansion induced a sharp increase in the number of recent immigrants - defined as foreign-born people who have been living in the UK for 5 years or less - from $2 \%$ to $4 \%$ of the population (Rienzo and Vargas-Silva, 2012). Another indicator of the growth in the migrant population is the trend in new immigrant GP registrations. As shown in Fig. 2, new immigrant GP registrations as a share of the total population in England increased from $0.9 \%$ in 2004 to $1.15 \%$ in 2010.

Waiting times decreased for outpatients and elective care between 2003 and 2012 and for A\&E between 2007 and 2012, as reported in Fig. 3. This outcome is partly the result of NHS policies implemented during this period. The NHS Plan in 2000 shifted the focus from the size of the waiting list to the maximum waiting times 

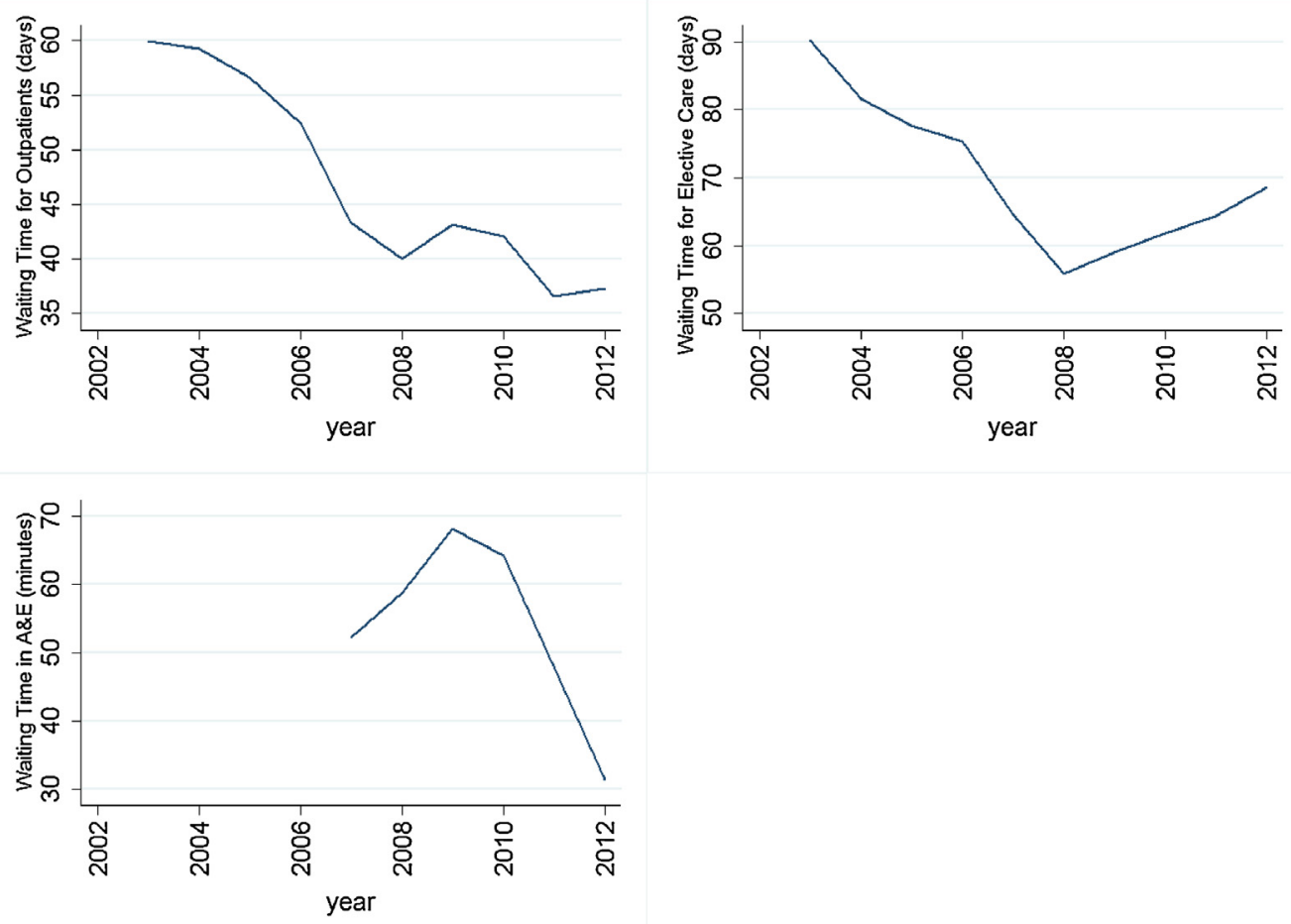

Fig. 3. Waiting times in the NHS (2003-2012). Notes - Data on average waiting times for outpatient services are drawn from the Hospital Episodes Statistics.

experienced by patients. In particular, the government adopted an aggressive policy of targets. The maximum wait for inpatient and day-case treatment was reduced from 18 to 6 months, while the maximum wait for an outpatient appointment was reduced from 6 to 3 months. Targets were coupled with the release of information on waiting times at the hospital level and strong sanctions for poorly performing hospital managers. These changes led to a significant reduction in the percentage of patients waiting at various points of the distribution of waiting times (Propper et al., 2008). Indeed since 2008, patients have the right to a maximum 18 week waiting time from referral to consultant. The formal introduction of waiting time targets of 18 weeks for $90 \%$ of in-patients and $95 \%$ of outpatients was introduced in 2008, right in the middle of our sample period. The 18 week waiting time target was adopted by individual hospital providers gradually adopted over the entire period. Waiting times went down in 2008 and remained relatively stable onward, although there has been an increase in waiting times for elective care since 2008 (see Fig. 3 and Appleby et al., 2014). ${ }^{6}$

Finally, we also use data on health status, self-reported disability and health care use from the Labor Force Survey, Understanding Society and General Household Survey (see the Data Appendix).

\subsection{Empirical specification}

In our baseline specification, we estimate the following model:

$w_{i t}=\alpha+\beta S_{l t}+X_{i t}^{\prime} \gamma+Z_{p t}^{\prime} \lambda+\mu_{p}+\eta_{t}+\epsilon_{i t}$,

where $w_{i t}$ is the average waiting time (for outpatients, elective care, or A\&E) in LSOA $i$ belonging to the PCT $p$ at time $t$; $S_{l t}$ is the share of immigrants in local authority $l$ at time $t ; X_{i t}^{\prime}$ is a vector of time-varying LSOA characteristics (index of deprivation and rural indicator); $Z_{p t}^{\prime}$ is a vector of time-varying characteristics at the PCT

\footnotetext{
${ }^{6}$ For a more detailed analysis of recent trends in NHS waiting times, see also the 2014 Department of Health Report: https://www.nao.org.uk/wp-content/uploads/ 2014/01/NHS-waiting-times-for-elective-care-in-England.pdf.
}

level, and $\mu_{p}$ and $\eta_{t}$ are PCT and year fixed effects, respectively; and $\epsilon_{i t}$ captures the residual variation in waiting times. Using LSOA fixed effects we do not have enough variation to identify the effects of immigration. ${ }^{7}$ To capture time-invariant characteristics that may be correlated with both waiting times and immigration inflows we control for PCT fixed effects. Time-varying LSOA characteristics include an Index of Deprivation (we use dummies for each decile of the index) and an indicator for rural status, the share of women, and the share of over 65 in the LSOA population. PCT time-varying characteristics include the ratio of occupied hospital beds to population, number of GPs per capita, number of GP practices per capita, number of health consultants per capita, health expenditure per capita, incidence of most common diseases. ${ }^{8}$ We also check the sensitivity of our result to the inclusion of LSOA population. ${ }^{9}$

For any given LSOA, the capacity of the nearest hospital is likely to determine the average waiting time. LSOAs served by the same hospitals would therefore share common determinants of waiting times. Thus, to control for potential confounders, we include nearest NHS trust fixed effects instead of PCT fixed effects as a robustness check.

In the estimations we show results using the contemporaneous value for the share of immigrants living in a local authority. However, as a robustness check, we consider lagged values of the share of immigrants (see the Appendix).

Our specification follows recent studies analyzing the impact of immigration (Orrenius and Zavodny, 2015; Foged and Peri, 2016; Giuntella and Mazzonna, 2015). The effect of immigration on waiting times is identified from spatial correlations between changes in the foreign-born stock and changes in waiting times across local

\footnotetext{
7 It is worth noting that the point-estimates obtained using LSOA fixed effects are not-significantly different from those presented in the main tables, but the standard errors increase by one order of magnitude. Results are available upon request.

8 Please note that these variables are only available at the PCT level.

9 Another possible approach is to estimate the model using first differences at the LA level (see Bell et al., 2013). That approach provides similar findings to the one using fixed effects (see also Wooldridge, 2002). Please section 4.4 for further details.
} 
authorities. The use of geographical variation in the share of immigrants (often called an "area approach") has been criticized by scholars (e.g., Borjas et al., 1996; Borjas, 2003) for two main reasons. First, natives may respond to the impact of immigration on a local area by moving to other areas. This is important in our study as health may be endogenous to the migration decision. Following Borjas et al. (1996), we test the robustness of our results to a change in the geographical unit using a higher level of aggregation. Furthermore, we analyze the effects of immigration on native internal mobility and examine whether waiting times were affected by native internal inflows across local authorities.

The second critique of the area approach is that immigrants might endogenously cluster in areas with better economic conditions. In our case, factors that attract more immigrants, such as economic growth, may lead to a downward bias in the effect of interest based on the long-stablished negative short-run correlation between the economic cycle and health (Ruhm, 2000). Furthermore, the presence of measurement error in the immigration share is likely to introduce attenuation bias, further exacerbated by the use of a large number of local area fixed effects (Wooldridge, 2002; Aydemir and Borjas, 2011). To address these concerns, we adopt an instrumental variable approach. Following Altonji and Card (1991), Card (2001), Bell et al. (2013) and Sá (2015), we use an instrumental variable based on a "shift share" of national levels of immigration into local authorities to impute the supply-driven increase in immigrants in each local authority.

The instrument exploits the fact that immigrants tend to locate in areas that have higher densities of immigrants from their same country of origin. We use this persistence in location choices of immigrants to distribute the annual national inflow of immigrants from a given country of origin across local authorities using the geographical distribution of immigrants from that same country in the 1991 UK Census. Using the geographical distribution of immigrants in 1991, we reduce the risk of endogeneity because annual immigration inflows across local authorities might be driven by time-varying characteristics of the local authority that are associated with health outcomes. ${ }^{10}$

Specifically, lets define $F_{c t}$ as the total population of immigrants from country $c$ residing in England in year $t$ (e.g., the number of Indians in England in 2012) and $F_{c l t}$ as the total population of immigrants from country $c$ residing in England in year $t$ and local authority $l$ (e.g., the number of Indians who resided in Oxford in 2012). Also, define $s_{c l t}$ as the local authority share of the total population of immigrants from country $c$ residing in England in year $t$ (e.g., the share of Indians in England who resided in Oxford in 2012). Finally, let $P_{l t}$ be the total population of local authority $l$ in year $t$.

Following a common approach in the literature (see for instance Orrenius and Zavodny, 2015; Foged and Peri, 2016), we then construct $\hat{F}_{c l t}$, the imputed population from country $c$ in local authority $l$ in year $t$, as follows:

$\hat{F}_{c l t}=s_{c l, 1991} * \Delta F_{c t}+F_{c l, 1991}$

Thus, the predicted number of new immigrants from a given country $c$ in year $t$ who reside in local authority $l$ is obtained by redistributing the national inflow of immigrants from that country

\footnotetext{
10 Table A1 illustrates the changes in stocks and shares of immigrant between the 1991 and the 2011 UK Census for the main source countries. The top 10 countries of birth of migrants according to the 2011 Census (England and Wales) are: India (694,000), Poland $(579,000)$, Pakistan $(482,000)$, Ireland $(407,000)$, Germany $(274,000)$, Bangladesh $(212,000)$, Nigeria $(191,000)$, South Africa $(191,000)$, USA $(177,000)$ and Jamaica $(160,000)$. However, considering the \% growth since the 2001 Census for these countries it is easy to see that Poland has dominated the inflow of migrants during the last decade: India (52\%), Poland (897\%), Pakistan (56\%), Ireland $(-13 \%)$, Germany (12\%), Bangladesh (38\%), Nigeria (120\%), South Africa (44\%), USA (23\%) and Jamaica (10\%)
}

based on the distribution of immigrants from that country across local authorities as of 1991.

Summing across all countries of origin, we obtain a measure of the predicted immigrant share of the population in local authority $l$ in year $t$. That is:

$\hat{S}_{l t}=\sum_{c} \frac{\hat{F}_{c l t}}{P_{l, 1991}}$

The variation of $\hat{S}_{l t}$ is driven only by changes in the imputed foreign population (the denominator is held fixed at its 1991 value) and is used as an instrument for the actual share of immigrants in local authority $l$ at time $t\left(S_{l t}\right)$. In practice, we divide immigrants into nine regions of origin: Africa, Americas and Caribbean, Bangladesh and Pakistan, India, Ireland, EU-15, Poland, and rest of the world.

One potential threat to the validity of this approach is that the instrument cannot credibly address the resulting endogeneity problem if the local economic shocks that attracted immigrants persist over time. However, this problem is substantially mitigated by including PCT fixed effects and by controlling for time-varying characteristics at the LSOA and PCT levels; thus, we can reasonably assume that past immigrant concentrations are not correlated with current unobserved local shocks that might be correlated with health. Under the assumption that the imputed inflow of immigrants is orthogonal to the local specific shocks and trends in labor market conditions after controlling for PCT and year fixed effects and time-varying characteristics of LSOAs and PCTs, the exclusion restriction holds. ${ }^{11}$

\section{Results}

\subsection{Waiting times for outpatients}

Table 2 presents the main results on the effects of immigration on waiting times for outpatients. In column 1, we report the OLS estimate controlling for year and PCT fixed effects. The coefficient is negative and statistically significant. An increase in the stock of immigrants equal to $10 \%$ of the initial local authority's population (approximately 1 standard deviation, see Table 1 ) decreases the average waiting time for outpatients by approximately 3 days $(6 \%$ relative to the mean of the dependent variable). It is worth noting that the share of immigrants in the population has a large standard deviation (mean of 11.75 and s.d. of 10.99 , see Table 1 ). The coefficient becomes non-significant when we include LSOA and PCT time-varying characteristics (column 2). Including the LSOA population (column 3 ) does not substantially change the results, suggesting that the negative association between immigration and waiting times is not correlated with changes in the LSOA size. ${ }^{12}$

To account for the endogeneity of the immigrant distribution across local authorities, we then estimate a 2SLS regression using the typical shift-share instrumental variable approach explained above. In the first-stage regression, the F-statistic (17.11) is above the weak instrument threshold. The difference between OLS and IV estimates may be explained by the fact that fixed effects estimates are susceptible to attenuation bias due to measurement error (Wooldridge, 2002; Aydemir and Borjas, 2011). Furthermore, pull factors that attract more immigration, such as economic growth, may lead to a downward bias in the effect of interest based on

\footnotetext{
11 The exclusion restriction assumption may be also violated if individuals respond to expected immigration flows based on current stocks. For instance, an individua living in an area with a high concentration of Polish immigrants may expect a large inflow of Polish after the 2004 EU enlargement, and, hence change their healthcare utilization for non-emergency conditions.

12 Note that including the local authority population rather than the LSOA population yields similar results (coef. -0.933 , std. err. 0.460 ).
} 
Table 2

Immigration and waiting times (days) in the NHS (outpatients), 2003-2012.

\begin{tabular}{|c|c|c|c|c|c|c|}
\hline & $\begin{array}{l}(1) \\
\text { OLS }\end{array}$ & $\begin{array}{l}(2) \\
\text { OLS }\end{array}$ & $\begin{array}{l}\text { (3) } \\
\text { OLS }\end{array}$ & $\begin{array}{l}(4) \\
2 S L S\end{array}$ & $\begin{array}{l}(5) \\
2 S L S\end{array}$ & $\begin{array}{l}(6) \\
2 S L S\end{array}$ \\
\hline Share of immigrants & $\begin{array}{l}-0.324^{*} \\
(0.178)\end{array}$ & $\begin{array}{l}-0.163 \\
(0.158)\end{array}$ & $\begin{array}{l}-0.164 \\
(0.158)\end{array}$ & $\begin{array}{l}-1.575^{* *} \\
(0.701)\end{array}$ & $\begin{array}{l}-0.933^{* *} \\
(0.461)\end{array}$ & $\begin{array}{l}-0.935^{* *} \\
(0.461)\end{array}$ \\
\hline Year f.e. & YES & YES & YES & YES & YES & YES \\
\hline PCT f.e. & YES & YES & YES & YES & YES & YES \\
\hline LSOA time-varying characteristics & NO & YES & YES & NO & YES & YES \\
\hline LSOA population & NO & NO & YES & NO & NO & YES \\
\hline Observations & 287,092 & 287,092 & 287,092 & 287,092 & 287,092 & 287,092 \\
\hline Mean of dep. var. & 47.12 & 47.12 & 47.12 & 47.12 & 47.12 & 47.12 \\
\hline Std. dev. of dep. var. & 16.65 & 16.65 & 16.65 & 16.65 & 16.65 & 16.65 \\
\hline First-stage $F$ & & & & 17.11 & 16.07 & 16.05 \\
\hline
\end{tabular}

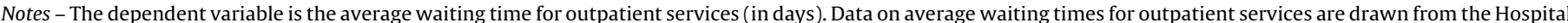

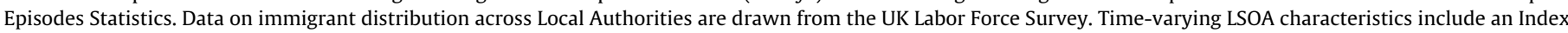

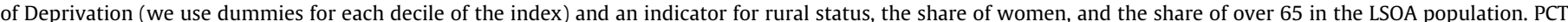

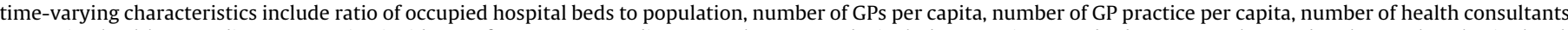

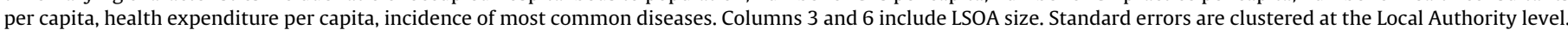

* Significant at the $10 \%$ level.

** Significant at the $5 \%$ level.

the well-known negative (short-run) correlation between the economic cycle and health (Ruhm, 2000).

Column 4 presents the second-stage estimates including only year and PCT fixed effects. The coefficient is negative and statistically significant. The coefficient diminishes by approximately $30 \%$ when including LSOA and PCT time-varying characteristics (column 5 ) but is still negative and significant, suggesting that an increase in the stock of immigrants equal to $10 \%$ of the initial local authority's population would reduce the average waiting time for outpatients by approximately 9 days (19\% relative to the mean of the dependent variable). Propper (1995) estimated that patients would be willing to pay GBP 80 (in 1991 prices) - roughly GBP 150 in 2013 prices - for a reduction of one month in waiting times. If disutility from the waiting list were linear, one could estimate that a 10day reduction in waiting time would be equivalent to GBP 37.5 in 2013 prices. Again, including population size (column 6) does not change the results. Overall, these results suggest that immigration was associated with a reduction in the average waiting time for outpatients.

\subsection{Waiting times in elective care}

In Table 3, we examine the effects of immigration on waiting times for elective care. The OLS estimate reported in column 2, which includes LSOA time-varying characteristics, year and PCT fixed effects, suggests that immigration is negatively associated with waiting time for elective care. An increase of 10 percentage points in the immigration share is associated with a 5-day reduction in the average waiting time for elective care (a $7 \%$ reduction relative to the average waiting time for elective care observed in the sample). However, the 2SLS estimate presented in column 4 is positive and non-significant, and the point estimate suggests a relatively small effect ( $+2 \%$ relative to the mean). The fact that waiting times for elective care were subject to performance management that lowered waiting times across England may explain the lack of significant effects of immigration in columns 4 to 6 of 33 . Also, it is important to note that only a small proportion of referrals end up in treatment and this could weaken the link between immigration and waiting times for elective care. For instance, in financial year $2013 / 2014$ only around $20 \%$ of the referrals ended up in elective care (NHS digital 2014). Finally, other non-price rationing mechanisms could be playing a role, including hospital activity and capacity. $^{13}$

\footnotetext{
13 See for instance Ham (2014).
}

\subsection{Waiting times in $A \mathcal{E} E$}

Table 4 illustrates the effects of immigration on waiting times for A\&E. Unfortunately, at the LSOA level, we have information only for the years 2007-2012. There is no evidence that immigrants have an effect on A\&E waiting times. The OLS estimates are negative and non-significant. The 2SLS estimate (column 4) is positive but it is estimated imprecisely. The point estimates are small (waiting times are reported in minutes). One possible explanation for the lack of effects on A\&E is that it is more "transient" immigrants who have not registered with a GP and would be more likely to use A\&E for non-urgent care. However, these results should be interpreted with caution because the analysis does not include the 2003-2006 period, in which immigration from A8 countries to the UK surged.

\subsection{Robustness checks}

\subsubsection{Alterative specifications}

As a robustness check, we replicate the analysis using nearest NHS trust fixed effects instead of PCT fixed effects. The coefficient of our preferred estimate is smaller, but not statistically different, than the one reported in Table 2 . The results suggest that an increase in the stock of immigrants equal to $10 \%$ of the initial local authority's population would reduce the average waiting time for outpatients by approximately 6 days, a reduction of $13 \%$ relative to the mean of the dependent variable (see Table A2 in the Appendix for details). We also confirm the non-significant effects for elective care and A\&E.

Using a first-difference approach estimates are not significantly different from the ones reported in our main specification (see Table A3). We also present the results mimicking the Bell et al. (2013) strategy and only exploiting the inflows of immigrants from A8 countries (see Table A4). Overall these estimates confirm our main results.

In addition, we test the robustness of our results on outpatient waiting times to a change in the geographical unit using a higher level of aggregation. Consistent with previous analyses by Borjas (2006) and Sá (2015), we find no evidence that immigration has a negative effect on waiting times when waiting times are aggregated at the regional level (see Table A5). While point estimates are not precise and the standard errors are very large because the sample is much smaller, the point estimate is much smaller than that presented in Table 2. A likely explanation of this result is that intra-region native mobility is causing diffusion of the effects of immigration within a region. Immigration may decrease waiting times at the local level, but the outflow of natives in response to 
Table 3

Immigration and waiting times (days) in the NHS (elective care - inpatients), 2003-2012.

\begin{tabular}{|c|c|c|c|c|c|c|}
\hline & $\begin{array}{l}\text { (1) } \\
\text { OLS }\end{array}$ & $\begin{array}{l}\text { (2) } \\
\text { OLS }\end{array}$ & $\begin{array}{l}\text { (3) } \\
\text { OLS }\end{array}$ & $\begin{array}{l}(4) \\
2 S L S\end{array}$ & $\begin{array}{l}(5) \\
2 S L S\end{array}$ & $\begin{array}{l}(6) \\
2 S L S\end{array}$ \\
\hline Share of immigrants & $\begin{array}{l}-0.103 \\
(0.317)\end{array}$ & $\begin{array}{l}-0.477^{*} \\
(0.261)\end{array}$ & $\begin{array}{l}-0.475^{*} \\
(0.262)\end{array}$ & $\begin{array}{l}0.204 \\
(0.597)\end{array}$ & $\begin{array}{l}0.203 \\
(0.596)\end{array}$ & $\begin{array}{l}0.208 \\
(0.597)\end{array}$ \\
\hline Year f.e. & YES & YES & YES & YES & YES & YES \\
\hline PCT f.e. & YES & YES & YES & YES & YES & YES \\
\hline LSOA time-varying characteristics & NO & YES & YES & NO & YES & YES \\
\hline LSOA population & NO & NO & YES & NO & NO & YES \\
\hline Observations & 287,092 & 287,092 & 287,092 & 287,092 & 287,092 & 287,092 \\
\hline Mean of dep. var. & 69.88 & 69.88 & 69.88 & 69.88 & 69.88 & 69.88 \\
\hline Std. dev. of dep. var. & 39.36 & 39.36 & 39.36 & 39.36 & 39.36 & 39.36 \\
\hline
\end{tabular}

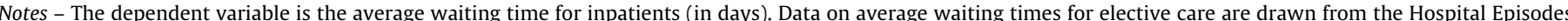

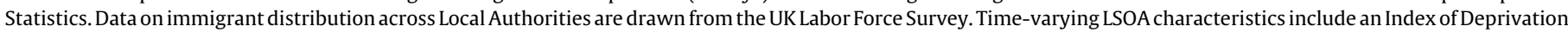

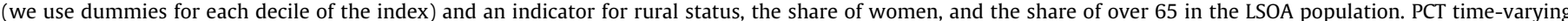

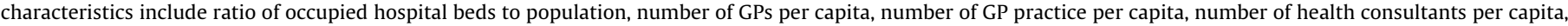
health expenditure per capita, incidence of most common diseases Columns 3 and 6 include LSOA size. Standard errors are clustered at the Local Authority level.

* Significant at the $10 \%$ level.

Table 4

Immigration and waiting times (min) in the NHS (A\&E), 2007-2012.

\begin{tabular}{|c|c|c|c|c|c|c|}
\hline & $\begin{array}{l}(1) \\
\text { OLS }\end{array}$ & $\begin{array}{l}(2) \\
\text { OLS }\end{array}$ & $\begin{array}{l}\text { (3) } \\
\text { OLS }\end{array}$ & $\begin{array}{l}(4) \\
2 S L S\end{array}$ & $\begin{array}{l}(5) \\
2 S L S\end{array}$ & $\begin{array}{l}(6) \\
2 S L S\end{array}$ \\
\hline Share of immigrants & $\begin{array}{l}-0.780 \\
(1.151)\end{array}$ & $\begin{array}{l}-0.522 \\
(0.978)\end{array}$ & $\begin{array}{l}-0.522 \\
(0.978)\end{array}$ & $\begin{array}{l}1.772 \\
(1.295)\end{array}$ & $\begin{array}{l}1.203 \\
(1.147)\end{array}$ & $\begin{array}{l}1.203 \\
(1.147)\end{array}$ \\
\hline Year f.e. & YES & YES & YES & YES & YES & YES \\
\hline PCT f.e. & YES & YES & YES & YES & YES & YES \\
\hline LSOA time-varying characteristics & NO & YES & YES & NO & YES & YES \\
\hline LSOA population & NO & NO & YES & NO & NO & YES \\
\hline Observations & 145,028 & 145,028 & 145,028 & 145,028 & 145,028 & 145,028 \\
\hline Mean of dep. var. & 55.30 & 55.30 & 55.30 & 55.30 & 55.30 & 55.30 \\
\hline Std. dev. of dep. var. & 65.53 & 65.53 & 65.53 & 65.53 & 65.53 & 65.53 \\
\hline
\end{tabular}

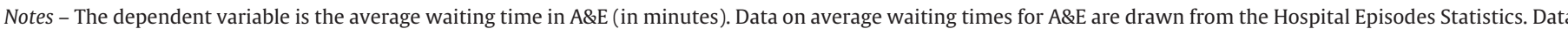

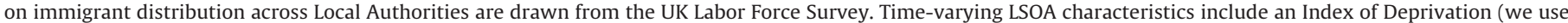

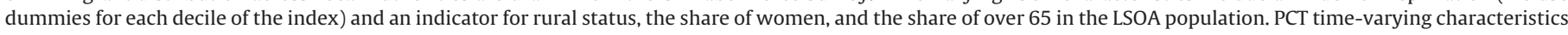

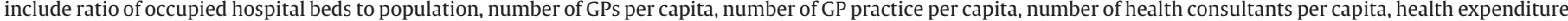
per capita, incidence of most common diseases Columns 3 and 6 include LSOA size. Standard errors are clustered at the Local Authority level.

immigration may increase waiting times in other local areas (we explore this mechanism in Section 5). Results for elective care and A\&E are not significant and largely imprecise.

\subsubsection{Alternative measures of waiting times}

In our baseline model we use average annual waiting times as the dependent variable. We also explore the results using the logarithm of waiting times and this does not change the main results (see Table A6 in the Appendix). As waiting time vary importantly during the year, with greatest pressure being felt during the winter months, waiting times for any individual provider are likely to be skewed. For this reason, as our data are drawn from individual episodes we also consider median waiting times as an alternative dependent variable. Using median waiting times, we confirm that immigration did not increase waiting times, and if anything, we confirm the reduction in outpatient waiting times (see Table A7).

We also considered as an alternative outcome the proportion of patients seen within the 18 weeks target (see Table A8). The formal introduction of waiting time targets of 18 weeks for $90 \%$ of in-patients and $9 \%$ of outpatients was introduced in 2008, but the 18 week waiting time target was gradually adopted by individual hospital providers over the entire period analyzed in this study. Our coefficients are less precisely estimated when using this alternative outcome. However, we confirm that - if anything - an increase in the share of immigrants (a 10 percentage point increase) was associated with a $20 \%$ reduction in the share of patients waiting more than 18 weeks for outpatient treatments. In line with our previous results we also find a positive but non-significant effect on waiting times for elective care.

\subsubsection{Alternative measures of immigration: data, lagged values, and placebo test}

Using the LFS to compute the stock of immigrants living in a local authority is subject to measurement error because in some local authorities, the share of immigrants in the LFS sample is low. Measurement error can result in substantial attenuation bias. Although using an instrumental variable based on census data and nationallevel inflows substantially mitigates this concern, as underlined by Sá (2015), we further check the robustness of our results using data from NINO registrations to overseas nationals from the Department for Work and Pensions.

Overseas nationals seeking to work, claim benefits or claim tax credits in the UK need a NINO. Thus, NINOs registrations of foreign nationals constitute an alternative source of information on immigrant inflows across local authorities. The main advantage of using NINOs data is that they are based on administrative records and provide a good measure of employment-driven migration (Lucchino et al., 2012). However, NINOs provide information only for the point and time of registration. Immigrants may change residence over time or leave the UK and return without having to re-register for a new NINO. We compute the stock of immigrants living in different local authorities using the 2001 Census data as a base for the initial stock of immigrants by the local authority and the NINOs data (available since 2002) to compute the evolution of the stock of immigrants by local authorities in the period under study (2003-2012). We replicate the main results presented in Tables 2 -Table 4 and find very similar results, thus confirming the negative effect on waiting times for outpatients and the non- 
significant effects on waiting times for elective care and A\&E (see Table A9 for details).

We also tested the sensitivity of our results to using lagged values of immigration. Overall, the results confirm our baseline estimates. In the Appendix, we report estimates obtained using the share of immigrants in a local authority at $t-3$ as our main covariate of interest (see Table A10).

In addition, to test for the concern of potential reverse causality (e.g., areas characterized by high waiting times at time $t$ receiving higher immigrant inflows at a later date), we examined the effect of the change in immigration between 2004 and 2012 on waiting times as of 2003 and found no evidence of any significant effect.

\subsubsection{Other outcomes: mortality rates, readmission rates, and number of GP referrals}

The focus of this study is on waiting times. However, we also investigated the effects of immigration on other measures of performance of the NHS. In particular, we examined the effect of immigration on re-admissions and mortality rates (see Table A11). We find no evidence that immigration had any significant impact on local authority re-admission rates and LSOA mortality rates. ${ }^{14}$

A relevant concern could be that immigration affected the referral behavior of GPs. While we cannot directly investigate how GPs change their behavior in response to immigration, we find no evidence that the number of GP referrals changed significantly in areas with a higher share of immigrants.

\section{Potential mechanisms}

In what follows, we focus on the analysis of the mechanisms underlying the result found on outpatient waiting times. The model presented above suggests that immigration may reduce waiting times by two main channels. Immigration may increase native internal mobility (see Sá, 2015). If immigration leads natives to move to different local authorities, the population size in the local authority may not change, and the health care demand may not increase. Moreover, natives may also seek care in the private sector, thus decreasing the pressure on local authorities where immigration is surging. At the same time, recent immigrant cohorts are relatively young and healthy upon arrival because of the "healthy immigrant effect" (Kennedy et al., 2014), suggesting that these immigrants may demand less care than what the NHS predicted (Wadsworth, 2013; Steventon and Bardsley, 2011). If immigrants are healthier and/or less likely to seek care, then waiting times may decrease even if the supply did not adjust.

To understand the possible mechanisms behind the negative effect of immigration on waiting times, we examine how immigration affected internal mobility and morbidity rates with respect to local authorities in England.

\subsection{Native mobility}

Several articles have explored the displacement effects of immigration. For the US, Card (2001) does not find evidence for displacement using US city data, while Borjas (2006) finds significant displacement effects. For the UK, Hatton and Tani (2005) find that for every 10 immigrants arriving in a region, 3.5 natives leave and move to other regions, while Sá (2015) finds even larger effects, suggesting a 1-to-1 immigrant-native displacement.

We analyze the displacement of the native population using the LFS data. We classify natives as having moved out of local authority $l$

\footnotetext{
14 Readmission rates measure the percentage of emergency admissions of people who returned to hospital as an emergency within 30 days of the last time they left hospital after a stay. Admissions for cancer and obstetrics are excluded as they may be part of the patient's care plan.
}

if they lived there in the previous year $(t-1)$ and currently, in year $t$, live in a different local authority. We then define the out-migration rate as the number of natives who moved out of local authority $l$ divided by the native population of local authority $l$ in year $t$. Similarly, we classify natives as having moved into local authority $l$ if they live there in year $t$ and were living in a different local authority in the previous year. We compute the in-migration rate as the ratio of the the number of natives who moved into local authority $l$ to the native population of $l$ in year $t-1$. The net out-migration rate is simply the difference between the out-migration and in-migration rates.

To examine the effect of immigration on native out-migration, in-migration and net out-migration rates, we estimate the following equation:

mobility $_{l t}=\beta \Delta F B_{l t} / P_{0 p} p_{l t-1}+\phi_{t}+\rho_{l}+\epsilon_{l t}$

The dependent variables (mobility ${ }_{l t}$ ) are the native outmigration, in-migration or net out-migration rate. The coefficient $\beta$ captures the change in mobility rates generated by an increase in foreign-born $(F B)$ population equal to $1 \%$ of the local authority population $\left(P o p_{l t-1}\right) . \phi_{t}$ and $\rho_{l}$ are respectively year and local authority fixed effects.

The estimation in Eq. (8) suffers from the same endogeneity problem as Eq. (5). Migrants are not randomly allocated across local authorities and this could lead to bias in the results. We address this problem using the same instrumental variable approach used in the previous section. While natives move for many reasons, the fact that we are using an instrumental approach based on the historical settlement patterns of the foreign-born should attenuate concerns about possible bias.

As shown in Table 5, our results suggest that an increase in the stock of immigrants equal to $1 \%$ of the local initial population increases the native out-migration rate by 16 percentage points and the native in-mobility rate by 6.2 percentage points. As a result, native net out-migration rate increases by 9.7 percentage points. ${ }^{15}$ Overall, our results are in the same direction as those obtained by Sá (2015) and Hatton and Tani (2005).

Native out-migration in response to immigration may increase demand for health care services in the local areas to which natives move to relative to the areas which they are leaving. To isolate changes in internal mobility induced by immigration, we use again the same instrumental variable strategy, instrumenting native mobility with the predicted inflows of immigrants across local authorities. In practice, given the strong relationship between the immigration and native mobility illustrated in Table 5, we exploit the correlation between historical settlements of immigrants and current immigrant distribution as a source of plausibly exogenous variation in native mobility. Our 2SLS estimates suggest that an increase of 1 percentage point in the native population relative to the resident population in the previous year increases the average waiting time for outpatients by approximately 6 days (13\% more relative to the mean of the dependent variable, Table 6 , column 1). The coefficient diminishes when we include LSOA time-varying characteristics (column 2) and does not change substantially when we control for population size. The effect of native out-migration on waiting times for elective care and $A \& E$ is insignificant (not reported). ${ }^{16}$

\footnotetext{
15 Consistent with these results, our findings indicate that an increase in the share of immigrants living in a local authority has no significant effects on the local authority population size.

16 For this analysis, we use the same instrumental strategy adopted in the previous sections.
} 
Table 5

Immigrant inflows and native internal mobility (LFS, 2004-2012).

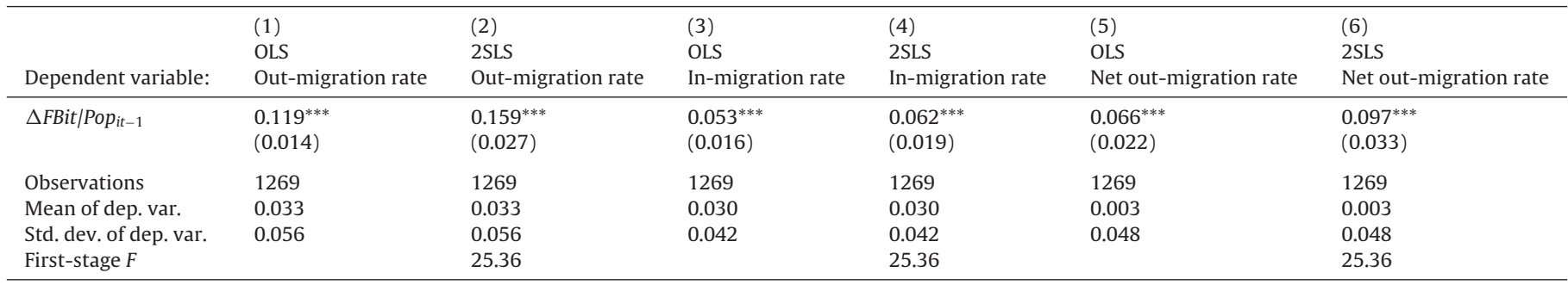

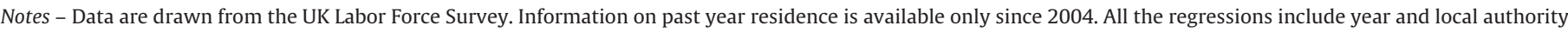
fixed effects and the standard errors are clustered at the Local Authority level.

Table 6

Native internal mobility and waiting times for outpatients (days), 2004-2012.

\begin{tabular}{llll}
\hline & $(1)$ & $(2)$ & $(3)$ \\
Dependent variable: & $\begin{array}{l}\text { 2SLS } \\
\text { Waiting time }\end{array}$ & $\begin{array}{l}\text { 2SLS } \\
\text { Waiting time }\end{array}$ & $\begin{array}{l}\text { 2SLS } \\
\text { Waiting time }\end{array}$ \\
\hline Net native migration & $5.689^{* * *}$ & $3.219^{* * *}$ & $3.227^{* * *}$ \\
& $(1.716)$ & $(1.138)$ & $(1.138)$ \\
Year f.e. & YES & YES & YES \\
PCT f.e. & YES & YES & YES \\
LSOA time-varying & NO & YES & YES \\
characteristics & & & \\
LSOA population & NO & NO & YES \\
Observations & 258,458 & 258,458 & 258,458 \\
Mean of dep. var. & 45.71 & 45.71 & 45.71 \\
Std. dev. of dep. var. & 15.64 & 15.64 & 15.64 \\
First-stage $F$ & 12.52 & 11.91 & 11.91 \\
\hline
\end{tabular}

Notes - The dependent variable is the average waiting time for outpatient services (in days. Data on average waiting times for outpatient services are drawn from the Hospital Episodes Statistics. Data on immigrant distribution across Local Authorities are drawn from the UK Labor Force Survey. Information on past year residence is available only since 2004. Time-varying LSOA characteristics include an Index of Deprivation (we use dummies for each decile of the index) and an indicator for rural status, the share of women, and the share of over 65 in the LSOA population. PCT time-varying characteristics include ratio of occupied hospital beds to population, number of GPs per capita, number of GP practice per capita, number of health consultants per capita, health expenditure per capita, incidence of most common diseases. Columns 3 includes LSOA size. Standard errors are clustered at the Local Authority level.

\subsection{Immigration and health}

As returns on migration are higher for healthier individuals, immigrants are likely to self-select migration based on health, along with other dimensions (e.g., education, Palloni and Morenoff, 2001; Jasso et al., 2004; Giuntella, 2013). Kennedy et al. (2014) show that this is particularly true for less educated immigrants, who have much better health outcomes than the average native person with low education.

The LFS contains questions on whether individuals had a health problem lasting more than 12 months and whether they have any disability (self-reported), ${ }^{17}$ and whether they had days off work because they were sick or injured in the reference week. Unsurprisingly, we find a positive and significant correlation between the incidence of individuals reporting health problems and disability and waiting times across English local authorities. For instance, an increase of 10 percentage points in the share of individuals reporting health problems is associated with a $9.3 \%$ increase in average waiting times for outpatients (results are available upon request). By changing the demographic composition of the population living in a local area, immigration may affect the share of individuals

17 We include both individuals who have a long-term disability that substantially limits their day-to-day activities and those who have a long-term disability that affects the kind or amount of work that they can do.
Table 7

Immigrant-native differences in health (LFS, 2004-2012).

\begin{tabular}{|c|c|c|c|}
\hline & (1) & (2) & (3) \\
\hline $\begin{array}{l}\text { Panel A: Any health issue } \\
\text { Foreign born }\end{array}$ & $\begin{array}{l}-0.075^{* * *} \\
(0.001)\end{array}$ & $\begin{array}{l}-0.046^{* * *} \\
(0.001)\end{array}$ & $\begin{array}{l}-0.049^{* * *} \\
(0.001)\end{array}$ \\
\hline Observations & $1,596,154$ & $1,551,640$ & $1,551,640$ \\
\hline $\begin{array}{l}\text { Mean of dep. var. } \\
\text { Std. dev. of dep. var. } \\
\text { Panel B: Any disability } \\
\text { Foreign born }\end{array}$ & $\begin{array}{l}0.317 \\
(0.465) \\
-0.039^{* * *} \\
(0.001)\end{array}$ & $\begin{array}{l}0.319 \\
(0.466) \\
-0.024^{* * *} \\
(0.001)\end{array}$ & $\begin{array}{l}0.319 \\
(0.466) \\
-0.029^{* * *} \\
(0.001)\end{array}$ \\
\hline Observations & $1,583,195$ & $1,538,633$ & $1,538,633$ \\
\hline $\begin{array}{l}\text { Mean of dep. var. } \\
\text { Std. dev. of dep. var. }\end{array}$ & $\begin{array}{l}0.220 \\
(0.414)\end{array}$ & $\begin{array}{l}0.222 \\
(0.416)\end{array}$ & $\begin{array}{l}0.223 \\
(0.416)\end{array}$ \\
\hline $\begin{array}{l}\text { Panel C: Absent at work due to illness } \\
\text { Foreign born }\end{array}$ & $\begin{array}{l}\text { injury } \\
-0.003^{* * *} \\
(0.001)\end{array}$ & $\begin{array}{l}-0.002^{* * *} \\
(0.001)\end{array}$ & $\begin{array}{l}-0.004^{* * *} \\
(0.000)\end{array}$ \\
\hline Observations & 983,229 & 938,668 & 938,668 \\
\hline $\begin{array}{l}\text { Mean of dep. var. } \\
\text { Std. dev. of dep. var. }\end{array}$ & $\begin{array}{l}0.023 \\
(0.152)\end{array}$ & $\begin{array}{l}0.023 \\
(0.151)\end{array}$ & $\begin{array}{l}0.023 \\
(0.151)\end{array}$ \\
\hline $\begin{array}{l}\text { Socio-demographic characteristics } \\
\text { Year f.e. } \\
\text { Local authority f.e. }\end{array}$ & $\begin{array}{l}\text { NO } \\
\text { NO } \\
\text { NO }\end{array}$ & $\begin{array}{l}\text { YES } \\
\text { YES } \\
\text { NO }\end{array}$ & $\begin{array}{l}\text { YES } \\
\text { YES } \\
\text { YES }\end{array}$ \\
\hline
\end{tabular}

Notes - Sociodemographic characteristics include gender, dummies for age, education, occupation (1-digit). Robust standard errors are reported in parentheses.

${ }^{* * *}$ Significant at the $1 \%$ level.

reporting health problems and disability and thus affect waiting times. To investigate this potential mechanism, in Table 7, we analyze immigrant-native differences in health using individual data from the LFS (2003-2012).

Panel A shows that foreign-born individuals are significantly less likely to report any health problem. In particular, the raw difference reported in column 1 shows that immigrants in England are 8 percentage points less likely to report a health problem lasting more than a year than natives. This is equivalent to a $25 \%$ difference with respect to the mean of the dependent variable in the sample (32\%). The difference becomes smaller when we account for age, education, gender and year fixed effects, indicating a difference of 4.6 percentage points equivalent to $15 \%$ of the mean (column 2 ). The coefficient remains stable when we include local authority fixed effects (column 3). In Panel B, we illustrate the difference in the likelihood of reporting any disability. On average, immigrants are 3.9 percentage points less likely to report any disability (column 1 ). The coefficient reduces to 2.4 percentage points when we account for sociodemographic characteristics, year fixed effects (column 2), and local authority fixed effects (column 3 ), revealing a $12 \%$ difference with respect to the incidence of disability in the sample (22\%). Immigrants are also less likely to take time off because of health problems. The conditional difference reported in column 3 of Panel C shows that foreign-born individuals are $17 \%$ less likely to be 
absent from work because of health problems than their UK-born counterparts. If we restrict the native sample to individuals who resided in a different local authority in the previous year we find that immigrants tend to be healthier than native internal migrants (see Table A12).

The fact that immigrants are healthier than native internal migrants in a context where immigration has significant effects on internal mobility can explain the lack of a significant increase in the demand for health care services and thus of waiting times. Consistent with previous literature on the healthy immigrant effect, the advantage is larger among recent cohorts of immigrants (columns 3-6). On the contrary, the differences are significantly smaller and only marginally significant when comparing the health of the internal migrants and the health of the residents of the destination area (Table A13).It is worth noting that while immigrants are in general healthier than out-migrants, the difference is not substantially different in more and less deprived areas (Table A14).

The health gap between the UK-born and the foreign-born are also confirmed with data from the Understanding Society survey (2009-2014). The Understanding Society data suggest that immigrants are less likely to report having a poor health status, any health limitation, or a disability (see Table A15 in the Appendix for details). This is particularly true for immigrants who arrived in England after 2000. The health immigrant advantage still remains when we control for sociodemographic characteristics such as gender, age, education, marital status, occupational category, region of residence, rural status, and year fixed effects. Given these findings, it is unsurprising that immigrants are less likely to use health care services than natives.

Using the same Understanding Society sample, we also illustrate differences between immigrants and natives in their health care use (see Table A16). Consistent with previous findings by Wadsworth (2013) and Steventon and Bardsley (2011), we find that recent immigrants are significantly less likely than natives to have consulted a GP and to have received treatment as outpatients or inpatients. Again, the results hold when we control for sociodemographic characteristics. ${ }^{18}$ We obtain similar results using the General Household Survey (see Table A17).

\subsection{Immigration and the supply of health care}

Thus far, we have focused on the effects of immigration on the demand for care and waiting times. However, immigration may also induce a rightward shift in supply, as many doctors and nurses come to the UK from overseas, increasing the supply of health care personnel. In this section, we analyze how immigration affects the supply of health care services by focusing on the number of GPs, the number of GPs who graduated abroad, specialists, GP practices, the ratio of occupied hospital beds to the population, and average NHS expenditure.

The results presented in Table 8 suggest that there is no significant association between immigration and the health care supply across England. As the NHS supply may not adjust immediately to immigration, we also replicate the same estimates using a model with long differences (between years $t$ and $t-3$ ) and confirm the lack of any significant effect on the supply side at the local level. ${ }^{19}$ Consistent with these results, using data on individual occupations

\footnotetext{
18 Dustmann and Frattini (2014) estimate that immigrants from the European Economic Area (EEA), particularly immigrants from countries that joined the EU in 2004 , made a positive fiscal contribution. Our results suggest that their estimates may be downward biased because they estimate the proportion of health services expenditure attributable to each group based on the groups age structure, yet we show that immigrants are healthier than natives in their same age group even after controlling for socioeconomic status and education.

19 The results are available upon request.
}

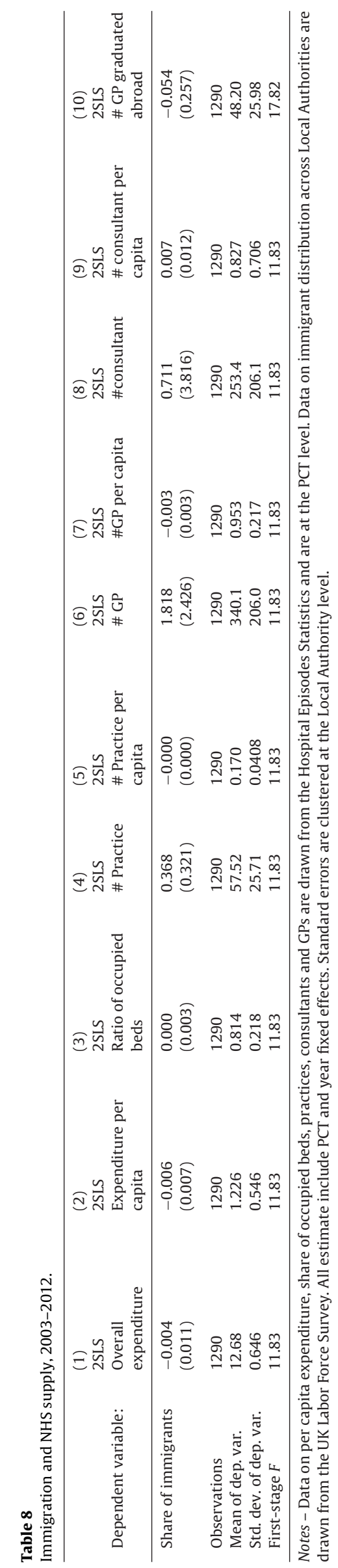


from the LFS 2003-2012, we find no evidence of a significant relationship between immigration and the proportion of health care personnel (professionals and clerical staff) and nurses in the population. Furthermore, when including the number of GPs, health care professionals and nurses in our main regression on waiting times, we find that the coefficient is not substantially affected. ${ }^{20}$

While the NHS is somewhat dependent on foreign-trained doctors and other foreign health care professionals, the lack of a significant association between immigration and the supply of health care may have several explanations. First, the large majority of immigrants do not work in the NHS, and this could affect the correlation between the share of immigrants and the staff size across local authorities. Indeed, using LFS data (2003-2012), we estimate that only $7 \%$ of the working-age immigrant population works in professional health care occupations, including medical doctors, dentists, pharmacists, nurses and midwives. Second, the vast majority of foreign-born health care professionals are concentrated in a few areas (e.g., London, Oxford), as local authorities with the highest provision of doctors and nurses are those with major cities/urban centers along with medical schools and teaching hospitals (Yar et al., 2006; Shutes, 2011). Third, many new immigrants working in the NHS could be substituting for natives or other immigrants and may not necessarily increase the supply of NHS staff.

It is also important to know that an important that an increase in the number of GPs may not necessarily reduce waiting time (Silvester et al., 2004). Previous studies analyzing the association between waiting lists and supply measures such as the number of consultants, the number of beds and hospital expenditure have found no clear pattern (Cullis et al., 2000). However, this is in contrast to Siciliani and Iversen (2012) who sum up previous empirical studies by saying that an increased in resources devoted to increase supply will have a significant effect in reducing waiting times.

\section{The heterogeneous impact of immigration across local authorities}

The extent of immigrant health selectivity is likely to differ among local authorities in England. Fig. 4 shows that both natives and immigrants in more deprived areas are more likely to report health problems lasting more than 12 months and disabilities. Unsurprisingly, Table A18 shows that individuals living in areas with an Index of Multiple Deprivation (IMD) above the median are, on average, less healthy than those living in less deprived areas. ${ }^{21}$ In particular, immigrants in deprived areas tend to be less favorably selected (see columns 5 and 6).

There is evidence that migrants moving to less deprived areas are healthier than migrants who move to more deprived locations, thus increasing health inequalities across areas (Norman et al., 2005). This suggests that the effects of immigration on waiting times may be very different in deprived areas, particularly as these are areas where the supply tends to be more inelastic, where the population faces higher mobility costs, and where waiting times tend to be longer (Laudicella et al., 2012).

\footnotetext{
${ }^{20}$ Immigrants represent a large and growing share of care workers in the UK who provide home care services for elderly natives (Shutes, 2011). While home care workers are unlikely to have any direct effect on waiting times, they may affect population access to NHS health care services by increasing early diagnosis and patient mobility. To verify whether our main result is partially explained by the increase in home care workers induced by immigration, we include the share of foreign-born home care workers as a control when analyzing the effect of immigration on waiting times. The coefficient is only marginally higher - and not statistically different than that found in our baseline specification. The results are available upon request.

21 Note that we exclude the health domain from the computation of the IMD score. The IMD score was calculated in 2003, 2007, and 2010 by the ONS. Thus, some local areas change their ranking over time.
}

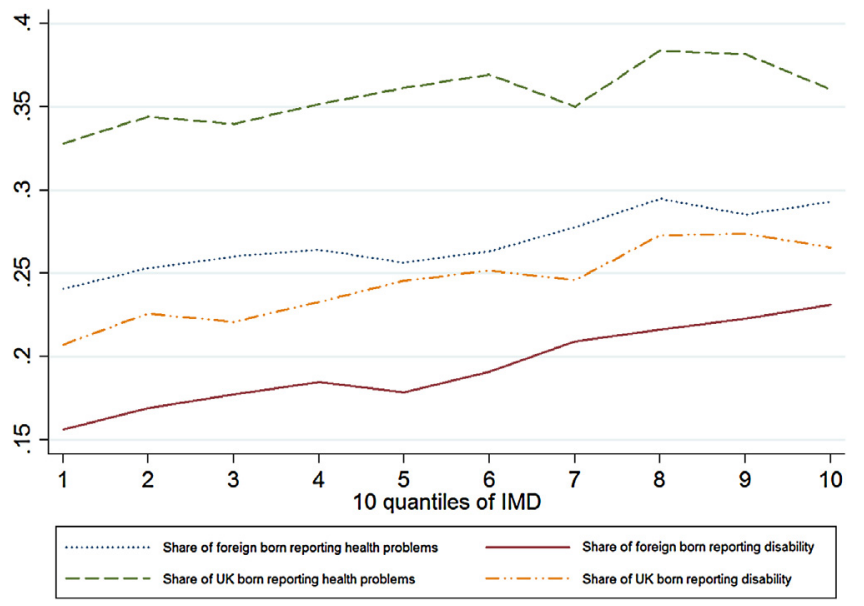

Fig. 4. Health by migrant status and Index of Multiple Deprivation (IMD) in England (2003-2012). Notes - Data are drawn from the UK Labor Force Survey.

\section{Table 9}

Immigration and waiting times (in days) for outpatients by Index of Multiple Deprivation (IMD) quintiles, 2003-2012.

\begin{tabular}{llllll}
\hline & $(1)$ & $(2)$ & $(3)$ & $(4)$ & $(5)$ \\
& $2 S L S$ & $2 S L S$ & $2 S L S$ & $2 S L S$ & $2 S L S$ \\
& Q1 & Q2 & Q3 & Q4 & Q5 \\
\hline Share of immigrants & -0.893 & $-0.730^{* * *}$ & $-0.669^{* * *}$ & $-0.549^{* * *}$ & -0.277 \\
& $(0.543)$ & $(0.234)$ & $(0.213)$ & $(0.201)$ & $(0.193)$ \\
Region f.e & YES & YES & YES & YES & YES \\
Year f.e. & YES & YES & YES & YES & YES \\
Observations & 57,491 & 57,513 & 57,632 & 57,352 & 57,104 \\
$R$-squared & 0.319 & 0.344 & 0.374 & 0.428 & 0.475 \\
Mean of dep. var. & 45.69 & 46.24 & 47.29 & 48.19 & 48.22 \\
Std. dev. of dep. var. & 15.17 & 16.40 & 16.75 & 17.33 & 17.34 \\
First-stage $F$ & 9.44 & 14.29 & 13.39 & 33.07 & 72.14 \\
\hline
\end{tabular}

Notes - Data on average waiting times for outpatient services are drawn from the Hospital Episodes Statistics. Data on immigrant distribution across Local Authorities are drawn from the UK Labor Force Survey. Time-varying LSOA characteristics include an Index of Deprivation (we use dummies for each decile of the index) and an indicator for rural status, the share of women, and the share of over 65 in the LSOA population. PCT time-varying characteristics include hospital beds' availability, number of GPs per capita, number of GP practice per capita, number of health consultants per capita, health expenditure per capita, incidence of most common diseases. Columns 3 and 6 include LSOA size. Standard errors are clustered at the Local Authority level.

*** Significant at the $1 \%$ level.

In Table 9, we explore this further by estimating the impact of immigration on outpatient waiting times based on the level of deprivation of the area. ${ }^{22}$ The results show that the negative effect on waiting times for outpatients is driven by less deprived areas. Columns 1-5 report the estimates of the main effect for LSOAs in the different quintiles of the IMD distribution. The table shows that the negative effect is largest (in absolute value) for LSOAs in the less deprived areas (Q1) and smallest for LSOAs in the more deprived areas (Q5), with the coefficient decreasing monotonically along the IMD distribution. ${ }^{23}$

We also investigate whether there are any specific short-term effects of immigration in deprived areas and whether the results are affected by the inclusion of London, the region that has the largest concentration of immigrants and the largest health care supply in

\footnotetext{
22 We replicate Table 10 for waiting times in elective care and A\&E but find no evidence of significant effects even when restricting the analysis to deprived areas outside of London.

${ }^{23}$ Note that in Table 9, we include region fixed effects rather than PCT fixed effects, as the smaller sample size of each quintile does not allow us to have sufficient identification power when using PCT fixed effects.
} 
Table 10

Immigration and waiting times (days) for outpatients, by Index of Multiple Deprivation (IMD).

\begin{tabular}{|c|c|c|c|c|c|}
\hline & $\begin{array}{l}(1) \\
\text { 2SLS } \\
\text { Overall } \\
\text { 2003-2012 }\end{array}$ & $\begin{array}{l}(2) \\
\text { 2SLS } \\
\text { Overall } \\
2003-2007\end{array}$ & $\begin{array}{l}(3) \\
\text { 2SLS } \\
\text { Outside London } \\
2003-2007\end{array}$ & $\begin{array}{l}(4) \\
\text { 2SLS } \\
\text { Outside London } \\
2003-2007 \\
\text { More deprived areas }(6-10)\end{array}$ & $\begin{array}{l}(5) \\
\text { 2SLS } \\
\text { Outside London } \\
\text { 2003-2007 } \\
\text { More deprived areas (7-10) }\end{array}$ \\
\hline Share of immigrants & $\begin{array}{l}-0.935^{* *} \\
(0.461)\end{array}$ & $\begin{array}{l}-0.818^{* * *} \\
(0.317)\end{array}$ & $\begin{array}{l}0.479 \\
(0.350)\end{array}$ & $\begin{array}{l}1.499^{*} \\
(0.788)\end{array}$ & $\begin{array}{l}2.085^{*} \\
(1.143)\end{array}$ \\
\hline Year f.e. & YES & YES & YES & YES & YES \\
\hline PCT f.e. & YES & YES & YES & YES & YES \\
\hline LSOA time-varying & YES & YES & YES & YES & YES \\
\hline characteristics & YES & YES & YES & YES & YES \\
\hline LSOA population & YES & YES & YES & YES & YES \\
\hline Observations & 287,092 & 144,476 & 122,067 & 57,146 & 44,964 \\
\hline Mean of dep. var. & 47.12 & 54.26 & 51.49 & 52.03 & 52.01 \\
\hline Std. dev. of dep. var. & 16.65 & 17.27 & 15.40 & 16.04 & 16.27 \\
\hline First-stage $F$ & 16.05 & 28.72 & 54.54 & 20.60 & 14.09 \\
\hline
\end{tabular}

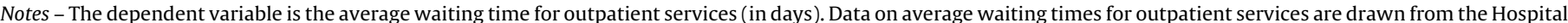

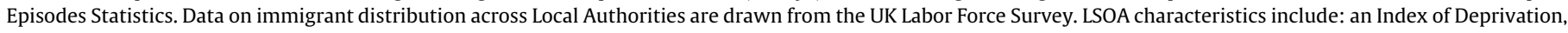

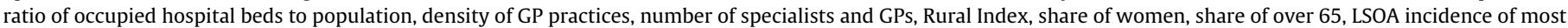
common diseases and LSOA size. Standard errors are clustered at the Local Authority level.

* Significant at the $10 \%$ level.

** Significant at the 5\% level.

*** Significant at the $1 \%$ level.

England. We find that the results are affected by the exclusion of London and the focus on more deprived areas of England before 2008. In particular, columns 4-5 of Table 10 show that immigration had a heterogeneous impact across England and that, at least in the first years following the 2004 EU enlargement, immigration increased the average waiting time in deprived areas outside of London. Column 4 shows that in the first three years after the 2004 EU enlargement, an increase of 10 percentage points in the share of immigrants living in a local authority increased waiting times by approximately 14 days (a $25 \%$ increase relative to the mean of the dependent variable) when we restrict the analysis to local authorities with an IMD above the median. The effect becomes even larger (20 days, $+38 \%$ of the mean of the dependent variable) when the sample is limited to the 4 highest deciles of the IMD. With the estimates of Propper (1995) on the cost of waiting time, an average increase of 20 days in waiting time would be equivalent to GBP 100 (in 2013 prices) per patient.

As shown in Fig. 4 and Table A18, deprived areas attract immigrants with worse health status. One of the factors contributing to the higher morbidity of immigrants moving into more deprived areas may be the greater presence of non-economic immigrants. Previous studies for the UK and other countries have shown that refugees and asylum seekers have worse health than economic migrants (Chiswick et al., 2008). In the UK, most asylum seekers are assigned to local areas by the UK government based on space and logistical considerations. However, as noted by Bell et al. (2013), asylum seekers are disproportionately sent to deprived areas. Using data from the Home Office Immigration Statistics confirms this result in Fig. 5.

In Table A19, we show that a larger number of asylum seekers in a local authority is associated with higher waiting times. Columns 1 and 2 report OLS estimates including PCT and year fixed effects (column 2). Columns 3 and 4 repeat this analysis for asylum seekers in dispersal accommodation. The coefficient is positive but becomes non-significant when we include year fixed effects. The sign of this relationship between the share of asylum seekers and the average waiting time for outpatients is confirmed when using asylum seekers in dispersal accommodation to instrument for the total number of asylum seekers in an area (column 5), as in (Bell et al., 2013). Again, the coefficient is not precisely estimated when we include year fixed effects (column 6), and the estimated effect is relatively

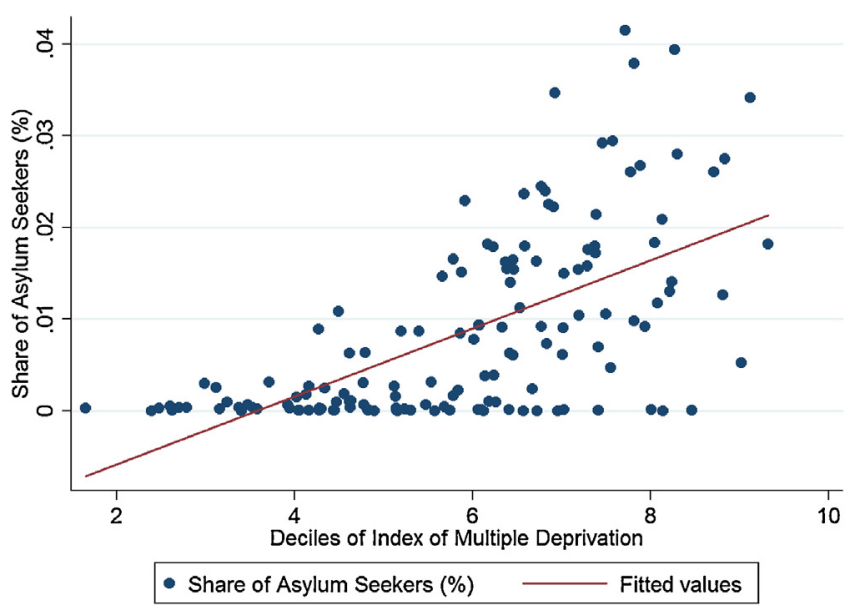

Fig. 5. Share of asylum seekers in the population by Index of Multiple Deprivation (IMD) in England (2003-2012). Notes - Data are drawn from the UK Home Office (2003-2012).

small: one standard deviation in the share of asylum seekers is associated with an approximately $1 \%$ increase in waiting times relative to the mean of the dependent variable. However, these results suggest that the larger presence of asylum seekers in deprived areas may contribute to the increase in waiting times shown in Table 10.

\section{Conclusion}

Immigrants' free access to the NHS and the perceived associated health care costs have generated much debate in the UK and have even resulted in the introduction of a fee for non-EU citizens to access NHS services. While previous papers have analyzed the effect of immigration to the UK on welfare use and documented differences in health care use between foreign-born individuals and natives, we know less about the effects of immigration on NHS waiting times, which is one of the most pressing issues for the NHS system.

This article contributes to the previous literature by estimating the effects of immigration on NHS waiting times in England. We find that immigration has reduced waiting times for outpatient refer- 
rals. An increase of 10 percentage points in the share of migrants living in a local authority would reduce waiting times by 9 days on average. We find no evidence that immigration affects waiting times in A\&E and in elective care. Based on our estimates, we can only conclude that there was a reduction in outpatient waiting times and no evidence of significant effects on waiting times for elective care, and evidence of no-effect in A\&E. However, weighting waiting times by the number of episodes in different areas of care (source: NHS Digital), we estimated that a 10 percentage point increase in the share of migrants living in a local authority would reduce the overall waiting times by 8 days on average.

Our main results are likely to be driven by two key factors. First, migrants tend to be young and healthy upon arrival (healthy immigrant effect) and are likely to have a smaller impact on the demand for NHS services. Second, the arrival of immigrants increases the likelihood of natives moving and accessing health services in a different local authority. Thus, the effects of immigration on the demand for health care services are dispersed throughout the country (via internal migration).

The historical context related to this study is also important. First, the analysis takes place in period at which the English government adopted an aggressive policy of targets and sanctions to reduce NHS waiting times. These policies proved to be effective in decreasing average waiting times in England (Propper et al., 2008). However, our results suggest that high levels of immigration during the same period also led to a relative decrease in waiting times across English local authorities, which suggest that in average some local authorities (i.e., those receiving a substantial inflow of immigrants) benefited from both effects during this period. Other local authorities are likely to have experienced smaller decreases in waiting time that would have been the case without the high levels of immigration that England experienced during this period.
Second, during this period the NHS in England also adopted a policy of providing additional funding to more deprived areas. The evidence suggests that this policy reduced the health gradient between more deprived and more affluent areas of England (Barr et al., 2014). In this case, the results go in the opposite direction and immigration might have limited the reduction in the health gap between some more and less deprived areas. In particular, we observe a positive impact of immigration on outpatient waiting times in the years immediately following the 2004 EU enlargement in the more deprived areas outside of London. This effect is partly explained by the fact that less healthy immigrants tend to move into more deprived areas, thereby increasing the demand for NHS services in those areas. Another driving factor is the lower mobility of natives in deprived areas, particularly among those with health problems.

Our results suggest that if funding mechanisms do not fully reflect changes in population need and less healthy immigrants are more concentrated in areas where the native born population is also less healthy and less mobile, then any negative impact of immigration will be concentrated in these areas. While this clearly goes beyond the scope of this paper, it is worth noting that this may in turn lead to increase support for more restrictive migration policies in these areas. Finally, our study focuses on a relatively short period of time and thus can only capture short and medium-run effects. As the health of immigrants converges to that of natives over time, immigrants may demand more health care services. Future research may shed light on the long-run effects of immigration on the demand for health care services and the performance of the receiving health care system.

\section{Appendix A.}

A. $1-$ A. 20

Table A1

Top 10 foreign countries of birth in 1991 Census (England and Wales).

\begin{tabular}{|c|c|c|c|c|}
\hline $\begin{array}{l}\text { Top } 10 \text { foreign countries of } \\
\text { birth in } 1991 \text { Census }\end{array}$ & Number in 1991 & Number in 2011 & $\begin{array}{l}\text { Share of all migrants in } 1991 \\
\text { Census }\end{array}$ & $\begin{array}{l}\text { Share of all migrants in } 2011 \\
\text { Census }\end{array}$ \\
\hline Ireland & 569,000 & 407,000 & $16 \%$ & $5 \%$ \\
\hline India & 400,000 & 694,000 & $11 \%$ & $9 \%$ \\
\hline Pakistan & 225,000 & 482,000 & $6 \%$ & $6 \%$ \\
\hline Germany & 202,000 & 274,000 & $6 \%$ & $4 \%$ \\
\hline Jamaica & 142,000 & 160,000 & $4 \%$ & $2 \%$ \\
\hline USA & 131,000 & 177,000 & $4 \%$ & $2 \%$ \\
\hline Kenya & 111,000 & 138,000 & $3 \%$ & $2 \%$ \\
\hline Bangladesh & 104,000 & 212,000 & $3 \%$ & $3 \%$ \\
\hline Italy & 87,000 & 134,000 & $2 \%$ & $2 \%$ \\
\hline Cyprus & 77,000 & $\mathrm{~N} / \mathrm{A}$ & $2 \%$ & $\mathrm{~N} / \mathrm{A}$ \\
\hline
\end{tabular}

Table A2

Immigration and waiting times (days) in the NHS (outpatients), nearest NHS Trust fixed-effects, 2003-2012.

\begin{tabular}{|c|c|c|c|c|c|c|}
\hline & $\begin{array}{l}\text { (1) } \\
\text { OLS }\end{array}$ & $\begin{array}{l}(2) \\
\text { OLS }\end{array}$ & $\begin{array}{l}\text { (3) } \\
\text { OLS }\end{array}$ & $\begin{array}{l}(4) \\
2 S L S\end{array}$ & $\begin{array}{l}(5) \\
2 S L S\end{array}$ & $\begin{array}{l}(6) \\
2 S L S\end{array}$ \\
\hline \multirow[t]{2}{*}{ Share of immigrants } & -0.081 & -0.113 & -0.114 & $-0.295^{* * *}$ & $-0.595^{* * *}$ & $-0.596^{* * *}$ \\
\hline & $(0.056)$ & $(0.088)$ & $(0.088)$ & $(0.088)$ & $(0.183)$ & $(0.184)$ \\
\hline Year f.e. & YES & YES & YES & YES & YES & YES \\
\hline Nearest NHS Trust f.e. & YES & YES & YES & YES & YES & YES \\
\hline LSOA time-varying characteristics & NO & YES & YES & NO & YES & YES \\
\hline LSOA population & NO & NO & YES & NO & NO & YES \\
\hline Observations & 287,092 & 287,092 & 287,092 & 287,092 & 287,092 & 287,092 \\
\hline Mean of dep. var. & 47.12 & 47.12 & 47.12 & 47.07 & 47.12 & 47.12 \\
\hline Std. dev. of dep. var. & 16.65 & 16.65 & 16.65 & 16.61 & 16.65 & 16.65 \\
\hline
\end{tabular}

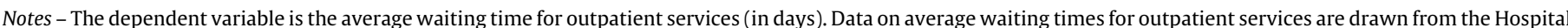

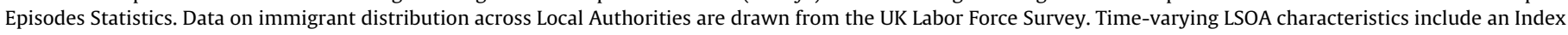

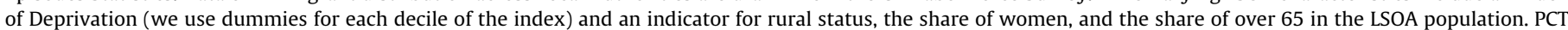

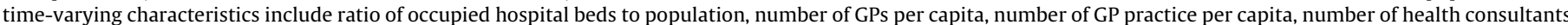

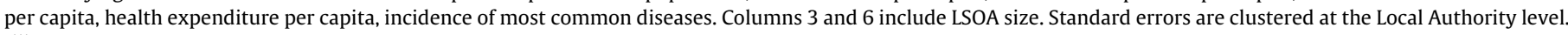

${ }^{* * *}$ Significant at the $1 \%$ level. 
Table A3

Immigration and waiting times, first-differences at local authority level (2SLS).

\begin{tabular}{llll}
\hline & $(1)$ & $(2)$ & $(3)$ \\
& 2SLS & 2SLS & 2SLS \\
Dependent variable: & Waiting time & Waiting time & Waiting time \\
& Outpatients & Elective care & A\&E \\
\hline$\Delta$ share of immigrants & $-1.187^{* * *}$ & -0.190 & 10.154 \\
Population & $(0.268)$ & $(0.709)$ & $(20.409)$ \\
Observations & 1288 & 1288 & 396 \\
\hline
\end{tabular}

Notes - Data on average waiting times are drawn from the Hospital Episodes Statistics. Data on immigrant distribution across Local Authorities are drawn from the Labor Force Survey. All estimate include controls for changes in the local authority population, time-varying characteristics at the LA-level (the share of women, the share of over 65, ratio of occupied hospital beds to population, number of GPs per capita, number of GP practice per capita, number of health consultants per capita, health expenditure per capita, incidence of most common diseases). Standard errors are clustered at the Local Authority level.

*** Significant at the $1 \%$ level.

Table A4

Immigration and waiting times (outpatients), first-difference analysis at local authority level.

\begin{tabular}{llll}
\hline & $(1)$ & $(2)$ & $(3)$ \\
\hline$\Delta$ share of immigrants from A8 countries & $-2.694^{* * *}$ & $-2.701^{* * *}$ & $-1.079^{* *}$ \\
& $(0.506)$ & $(0.507)$ & $(0.536)$ \\
LA population & & YES & YES \\
LA-time varying characteristics & & & YES \\
Observations & 1288 & 1288 & 1288 \\
\hline
\end{tabular}

Notes - Data on average waiting times are drawn from the Hospital Episodes Statistics. Data on immigrant distribution across Local Authorities are drawn from the Statistics on National Insurance Number (UK Department for Work and Pensions). All estimate include controls for changes in the local authority population, timevarying characteristics at the LA-level (he share of women, the share of over 65, ratio of occupied hospital beds to population, number of GPs per capita, number of GP practice per capita, number of health consultants per capita, health expenditure per capita, incidence of most common diseases). Standard errors are clustered the Local Authority level.

** Significant at the $5 \%$ level.

*** Significant at the $1 \%$ level.

Table A5

Immigration and outpatients waiting times, regional analysis, 2003-2012.

\begin{tabular}{lll}
\hline & $(1)$ & $(2)$ \\
& 2SLS & 2SLS \\
\hline Share of immigrants & -0.194 & -0.316 \\
& $(0.188)$ & $(0.251)$ \\
Year f.e. & YES & YES \\
Regional time-varying characteristics & YES & YES \\
Regional & NO & YES \\
Population & & \\
Observations & 160 & 160 \\
Mean of dep. var. & 45.42 & 45.42 \\
Std. dev. of dep. var. & 10.69 & 10.69 \\
First-stage $F$ & 396.1 & 324.6 \\
\hline
\end{tabular}

Notes - The dependent variable is the average waiting time for outpatient services (in days). Data on average waiting times for outpatient services are drawn from the Hospital Episodes Statistics. Data on immigrant distribution across Local Authorities are drawn from the UK Labor Force Survey. Standard errors are clustered at the regional level.
Table A6

Immigration and waiting times (logs) in the NHS outpatients, elective and A\&E.

\begin{tabular}{llll}
\hline & $(1)$ & $(2)$ & $(3)$ \\
& $\begin{array}{l}\text { 2SLS } \\
\text { Outpatients in } \\
\text { days }\end{array}$ & $\begin{array}{l}\text { 2SLS } \\
\text { Elective care in } \\
\text { days }\end{array}$ & $\begin{array}{l}\text { 2SLS } \\
\text { A\&E in minutes }\end{array}$ \\
\hline Share of immigrants & $-0.016^{* *}$ & 0.001 & 0.005 \\
& $(0.008)$ & $(0.006)$ & $(0.021)$ \\
Observations & 287,092 & 287,092 & 145,028 \\
Year f.e & YES & YES & YES \\
$\begin{array}{l}\text { PCT f.e } \\
\text { LSOA time-varying }\end{array}$ & YES & YES & YES \\
characteristics & YES & YES \\
Mean of dep. var. & 3.823 & 4.177 & 3.635 \\
Std. dev. of dep. var. & 0.315 & 0.385 & 0.878 \\
\hline
\end{tabular}

Notes - The dependent variable is the logarithm of the average waiting time in Outpatients (in days), elective (in days) and $\mathrm{A} \& \mathrm{E}$ (in min). Data on average waiting times are drawn from the Hospital Episodes Statistics. Data on immigrant distribution across Local Authorities are drawn from the UK Labor Force Survey. Time-varying LSOA characteristics include an Index of Deprivation (we use dummies for each decile of the index) and an indicator for rural status, the share of women, the share of over 65 in the LSOA population, and the LSOA population. PCT time-varying characteristics include ratio of occupied hospital beds to population, number of GPs per capita, number of GP practice per capita, number of health consultants per capita, health expenditure per capita, incidence of most common diseases. Standard errors are clustered at the local authority level.

** Significant at the $5 \%$.

Table A7

Immigration and median waiting times $(t), 2003-2012$.

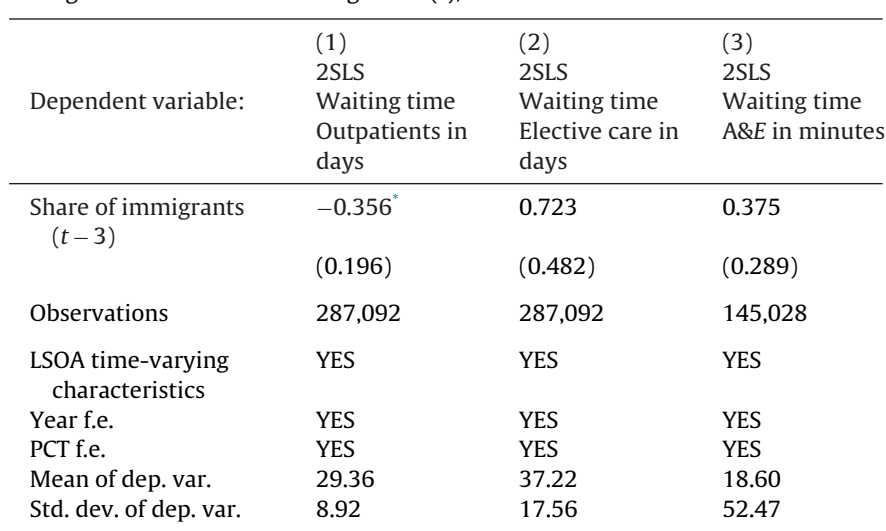

Notes - Data on average waiting times are drawn from the Hospital Episodes Statistics. Data on immigrant distribution across Local Authorities are drawn from the Labor Force Survey. Time-varying LSOA characteristics include an Index of Deprivation (we use dummies for each decile of the index) and an indicator for rural status, the share of women, the share of over 65 in the LSOA population, and the LSOA population. PCT time-varying characteristics include ratio of occupied hospital beds to population, number of GPs per capita, number of GP practice per capita, number of health consultants per capita, health expenditure per capita, incidence of most common diseases. Standard errors are clustered at the local authority level.

* Significant at the $10 \%$ level. 
Table A8

Immigration and proportion of patients waiting more than 18 weeks, 2003-2012.

\begin{tabular}{lll}
\hline & $(1)$ & $(2)$ \\
Dependent variable: & 2SLS & 2SLS \\
& Waiting time & Waiting time \\
& Outpatients & Elective care \\
\hline Share of immigrants & -0.001 & 0.0017 \\
& $(0.001)$ & $(0.002)$ \\
Observations & 287,092 & 287,092 \\
Mean of dep. var. & 0.036 & 0.141 \\
Std. dev. of dep. var. & $(0.028)$ & $(0.095)$ \\
LSOA time-varying characteristics & YES & YES \\
Year f.e. & YES & YES \\
PCT f.e. & YES & YES \\
\hline
\end{tabular}

Notes - Data on average waiting times are drawn from the Hospital Episodes Statistics. Data on immigrant distribution across Local Authorities are drawn from the Labor Force Survey. Time-varying LSOA characteristics include an Index of Deprivation (we use dummies for each decile of the index) and an indicator for rural status, the share of women, the share of over 65 in the LSOA population, and the LSOA population. PCT time-varying characteristics include ratio of occupied hospital beds to population, number of GPs per capita, number of GP practice per capita, number of health consultants per capita, health expenditure per capita, incidence of most common diseases. Standard errors are clustered at the local authority level.
Table A9

Immigration and waiting times, NINOs Data, 2003-2012.

\begin{tabular}{llll}
\hline & $(1)$ & $(2)$ & $(3)$ \\
Dependent variable: & $\begin{array}{l}\text { 2SLS } \\
\text { Waiting time } \\
\text { Outpatients }\end{array}$ & $\begin{array}{l}\text { 2SLS } \\
\text { Waiting time } \\
\text { Elective care }\end{array}$ & $\begin{array}{l}\text { WSLS } \\
\text { W\&E }\end{array}$ \\
\hline Share of immigrants & $-1.191^{* *}$ & 0.137 & 1.172 \\
& $(0.560)$ & $(0.738)$ & $(1.198)$ \\
Observations & 287,092 & 287,092 & 145,028 \\
$\begin{array}{l}\text { LSOA time-varying } \\
\text { characteristics }\end{array}$ & YES & YES & YES \\
$\begin{array}{l}\text { Year f.e. } \\
\begin{array}{l}\text { PCT f.e. } \\
\text { Mean of dep. var. }\end{array}\end{array}$ & YES & YES & YES \\
Std. dev. of dep. var. & 47.12 & YES & YES \\
\hline
\end{tabular}

Notes - Data on average waiting times are drawn from the Hospital Episodes Statistics. Data on immigrant distribution across Local Authorities are drawn from the Statistics on National Insurance Number (UK Department for Work and Pensions). Time-varying LSOA characteristics include an Index of Deprivation (we use dummies for each decile of the index) and an indicator for rural status, the share of women, the share of over 65 in the LSOA population, and the LSOA population. PCT time-varying characteristics include ratio of occupied hospital beds to population, number of GPs per capita, number of GP practice per capita, number of health consultants per capita, health expenditure per capita, incidence of most common diseases. Standard errors are clustered at the local authority level.

** Significant at the $5 \%$.

Table A10

Immigration $(t-3)$ and waiting times $(t), 2003-2012$.

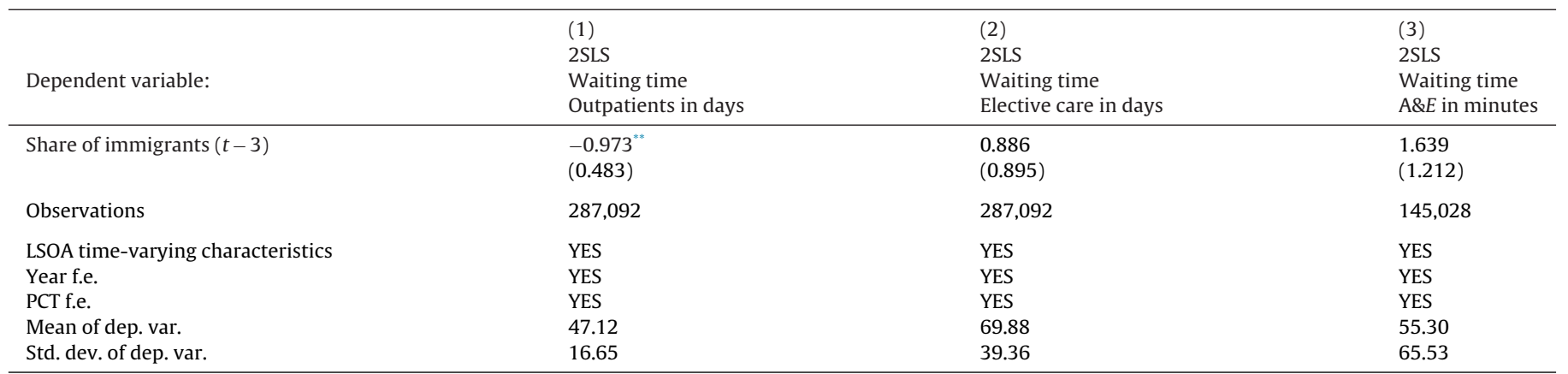

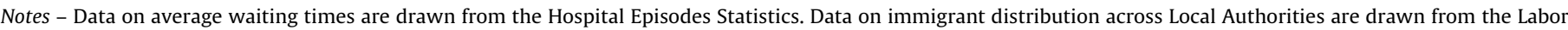

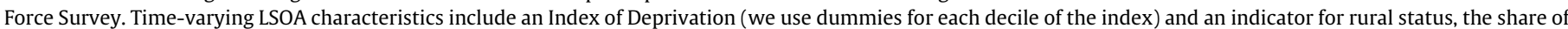

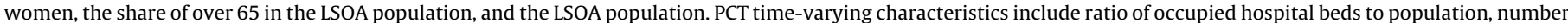

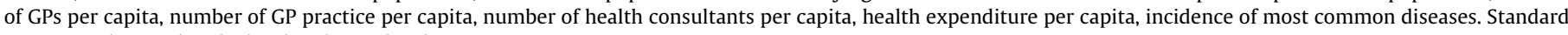
errors are clustered at the local authority level.

** Significant at the $5 \%$.

Table A11

Immigration and NHS: other outcomes, 2003-2012.

\begin{tabular}{|c|c|c|c|}
\hline & $\begin{array}{l}\text { (1) } \\
\text { Mortality rate per } 1000 \\
\text { LSOA } \\
\text { 2SLS }\end{array}$ & $\begin{array}{l}(2) \\
\text { Readmission rate } \\
\text { LA } \\
\text { 2SLS }\end{array}$ & $\begin{array}{l}\text { \# } 3 \text { GPs referrals rate (per 1000) } \\
\text { LSOA } \\
\text { 2SLS }\end{array}$ \\
\hline Share of immigrants & $\begin{array}{c}-0.003 \\
(0.007)\end{array}$ & $\begin{array}{l}0.047 \\
(0.0345)\end{array}$ & $\begin{array}{l}2.663 \\
(2.6119)\end{array}$ \\
\hline Observations & 254,749 & 263,438 & 287,092 \\
\hline Mean of dep. var. & 4.69 & 10.936 & 313.84 \\
\hline Std. dev. of dep. var. & 3.03 & 1.209 & 181.56 \\
\hline LSOA time-varying characteristics & YES & YES & YES \\
\hline Year f.e. & YES & YES & YES \\
\hline PCT f.e. & YES & YES & YES \\
\hline
\end{tabular}

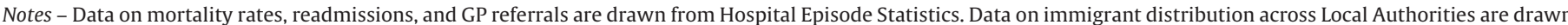

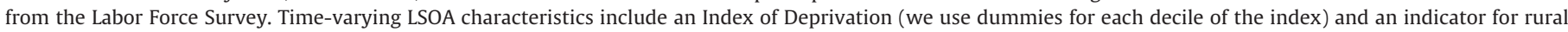

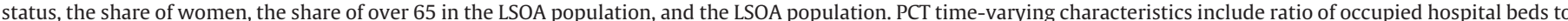

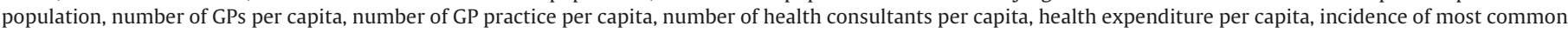
diseases. Standard errors are clustered at the local authority level. 
Table A12

Immigrant-native internal migrants differences in health (LFS, 2004-2012).

\begin{tabular}{|c|c|c|c|c|c|c|}
\hline & (1) & $(2)$ & (3) & $(4)$ & $(5)$ & (6) \\
\hline \multicolumn{7}{|l|}{ Panel A: Any health issue } \\
\hline Foreign born & $\begin{array}{l}-0.038^{* * *} \\
(0.005)\end{array}$ & $\begin{array}{l}-0.051^{* * *} \\
(0.004)\end{array}$ & & & & \\
\hline Foreign born arrived after 2000 & & & $\begin{array}{l}-0.106^{* * *} \\
(0.005)\end{array}$ & $\begin{array}{l}-0.072^{* * *} \\
(0.003)\end{array}$ & & \\
\hline Foreign born arrived after 2004 & & & & & $\begin{array}{l}-0.131^{* * *} \\
(0.005)\end{array}$ & $\begin{array}{l}-0.084^{* * *} \\
(0.003)\end{array}$ \\
\hline Observations & 166,078 & 162,869 & 96,854 & 95,655 & 62,649 & 62,401 \\
\hline Mean of dep. var. & 0.185 & 0.186 & 0.121 & 0.122 & 0.105 & 0.105 \\
\hline Std. dev. of dep. var. & 0.388 & 0.389 & 0.327 & 0.327 & 0.307 & 0.307 \\
\hline \multicolumn{7}{|l|}{ Panel B: Any disability } \\
\hline Foreign born & $\begin{array}{l}-0.026^{* * *} \\
(0.004)\end{array}$ & $\begin{array}{l}-0.039^{* * *} \\
(0.003)\end{array}$ & & & & \\
\hline Foreign born arrived after 2000 & & & $\begin{array}{l}-0.080^{* * *} \\
(0.004)\end{array}$ & $\begin{array}{l}-0.057^{* * *} \\
(0.003)\end{array}$ & & \\
\hline Foreign born arrived after 2004 & & & & & $\begin{array}{l}-0.101^{* * *} \\
(0.004)\end{array}$ & $\begin{array}{l}-0.069^{* * *} \\
(0.003)\end{array}$ \\
\hline Observations & 165,192 & 161,979 & 95,816 & 94,615 & 61,634 & 61,385 \\
\hline Mean of dep. var. & 0.138 & 0.139 & 0.0850 & 0.0854 & 0.0711 & 0.0711 \\
\hline Std. dev. of dep. var. & 0.344 & 0.346 & 0.279 & 0.279 & 0.257 & 0.257 \\
\hline \multicolumn{7}{|c|}{ Panel C: Absent at work due to illness or injury } \\
\hline Foreign born & $\begin{array}{l}-0.001 \\
(0.002)\end{array}$ & $\begin{array}{l}-0.004 \\
(0.002)\end{array}$ & & & & \\
\hline Foreign born arrived after 2000 & & & $\begin{array}{c}-0.004 \\
(0.002)\end{array}$ & $\begin{array}{l}-0.006^{* * *} \\
(0.002)\end{array}$ & & \\
\hline Foreign born arrived after 2004 & & & & & $\begin{array}{l}-0.006^{* *} \\
(0.002)\end{array}$ & $\begin{array}{l}-0.006^{* * *} \\
(0.002)\end{array}$ \\
\hline Observations & 109,582 & 106,369 & 63,004 & 61,803 & 39,494 & 39,245 \\
\hline Mean of dep. var. & 0.0216 & 0.0214 & 0.0200 & 0.0200 & 0.0186 & 0.0185 \\
\hline Std. dev. of dep. var. & 0.145 & 0.145 & 0.140 & 0.140 & 0.135 & 0.135 \\
\hline Sociodemographic characteristics & NO & YES & NO & YES & NO & YES \\
\hline Year f.e. & NO & YES & NO & YES & NO & YES \\
\hline Local authority f.e. & NO & YES & NO & YES & NO & YES \\
\hline
\end{tabular}

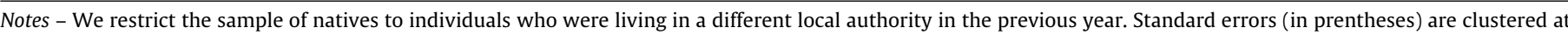

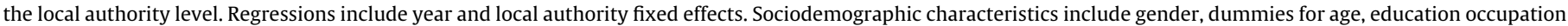
(1-digit).

* Significant at the $10 \%$ level.

** Significant at the 5\% level.

*** Significant at the $1 \%$ level.

Table A13

Differences in health between UK-born internal movers and UK-born non-movers (LFS, 2004-2012).

\begin{tabular}{|c|c|c|c|}
\hline & $\begin{array}{l}\text { (1) } \\
\text { Any health issue }\end{array}$ & $\begin{array}{l}(2) \\
\text { Any disability }\end{array}$ & $\begin{array}{l}\text { (3) } \\
\text { Absent at work due to illness or injury }\end{array}$ \\
\hline Mover & $\begin{array}{l}-0.007^{*} \\
(0.004)\end{array}$ & $\begin{array}{l}0.004 \\
(0.004)\end{array}$ & $\begin{array}{l}0.003 \\
(0.002)\end{array}$ \\
\hline Observations & 838,967 & 825,994 & 481,601 \\
\hline Mean of dep. var. & 0.314 & 0.222 & 0.0226 \\
\hline Std. dev. of dep. var. & 0.464 & 0.415 & 0.148 \\
\hline
\end{tabular}

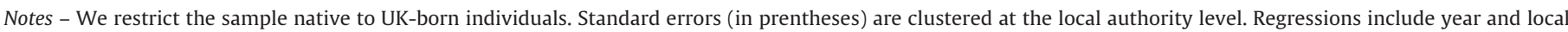
authority fixed effects. Sociodemographic characteristics include gender, dummies for age, education occupation (1-digit).

Table A14

Immigrant-native internal migrants differences in health (any health problem) by IMD (LFS, 2004-2012).

\begin{tabular}{|c|c|c|c|c|c|c|}
\hline & \multicolumn{3}{|c|}{ Less deprived areas (IMD $<5)$} & \multicolumn{3}{|c|}{ Highly deprived areas, IMD $\geq 5$} \\
\hline Foreign born & $\begin{array}{l}-0.041^{* * *} \\
(0.006)\end{array}$ & & & $\begin{array}{l}-0.059^{* * *} \\
(0.005)\end{array}$ & & \\
\hline Foreign born arrived after 2000 & & $\begin{array}{l}-0.069^{* * *} \\
(0.005)\end{array}$ & & & $\begin{array}{l}-0.076^{* * *} \\
(0.004)\end{array}$ & \\
\hline Foreign born arrived after 2004 & & & $\begin{array}{l}-0.082^{* * *} \\
(0.006)\end{array}$ & & & $\begin{array}{l}-0.090^{* * *} \\
(0.004)\end{array}$ \\
\hline Observations & 49,896 & 29,253 & 19,646 & 109,755 & 65,349 & 42,522 \\
\hline Mean of dep. var. & 0.169 & 0.118 & 0.109 & 0.194 & 0.124 & 0.103 \\
\hline Std. err. of dep. var. & 0.375 & 0.323 & 0.312 & 0.396 & 0.329 & 0.304 \\
\hline
\end{tabular}

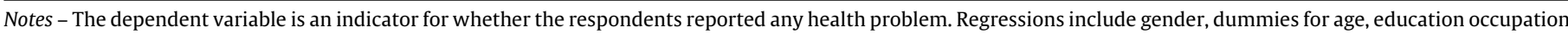
(1-digit), and year fixed effects.

*** Significant at the $1 \%$ level. 
Table A15

Immigrant health advantage (Understanding Society, 2009-2014).

\begin{tabular}{|c|c|c|c|c|c|c|}
\hline & (1) & $(2)$ & (3) & (4) & (5) & (6) \\
\hline \multicolumn{7}{|l|}{ Panel A: Poor health, waves 1-4 } \\
\hline Foreign born & $\begin{array}{l}-0.047^{* * *} \\
(0.007)\end{array}$ & $\begin{array}{l}-0.047^{* * *} \\
(0.007)\end{array}$ & & & & \\
\hline Foreign born came after 2000 & & & $\begin{array}{l}-0.134^{* * *} \\
(0.007)\end{array}$ & $\begin{array}{l}-0.134^{* * *} \\
(0.007)\end{array}$ & & \\
\hline Foreign born came after 2004 & & & & & $\begin{array}{l}-0.144^{* * *} \\
(0.008)\end{array}$ & $\begin{array}{l}-0.144^{* * *} \\
(0.008)\end{array}$ \\
\hline Observations & 67,584 & 67,584 & 62,711 & 62,711 & 61,565 & 61,565 \\
\hline Sociodemographic controls & NO & YES & NO & YES & NO & YES \\
\hline Mean of dep. var. & 0.193 & 0.193 & 0.190 & 0.190 & 0.192 & 0.192 \\
\hline Std. dev. of dep. var. & 0.394 & 0.394 & 0.393 & 0.393 & 0.394 & 0.394 \\
\hline \multicolumn{7}{|l|}{ Panel B: Disability, waves 1-4 } \\
\hline Foreign born & $\begin{array}{l}-0.127^{* * *} \\
(0.009)\end{array}$ & $\begin{array}{l}-0.127^{* * *} \\
(0.009)\end{array}$ & & & & \\
\hline Foreign born came after 2000 & & & $\begin{array}{l}-0.256^{* * *} \\
(0.010)\end{array}$ & $\begin{array}{l}-0.256^{* * *} \\
(0.010)\end{array}$ & & \\
\hline Foreign born came after 2004 & & & & & $\begin{array}{l}-0.276^{* * *} \\
(0.011)\end{array}$ & $\begin{array}{l}-0.276^{* * *} \\
(0.011)\end{array}$ \\
\hline Observations & 67,649 & 67,649 & 62,770 & 62,770 & 61,623 & 61,623 \\
\hline Sociodemographic controls & NO & YES & NO & YES & NO & YES \\
\hline Mean of dep. var. & 0.359 & 0.359 & 0.360 & 0.360 & 0.365 & 0.365 \\
\hline Std. dev. of dep. var. & 0.480 & 0.480 & 0.480 & 0.480 & 0.481 & 0.481 \\
\hline \multicolumn{7}{|c|}{ Panel C: Any health limitation, waves 1-4 } \\
\hline Foreign born & $\begin{array}{l}-0.018^{* * *} \\
(0.005)\end{array}$ & $\begin{array}{l}-0.018^{* * *} \\
(0.005)\end{array}$ & & & & \\
\hline Foreign born came after 2000 & & & $\begin{array}{l}-0.066^{* * *} \\
(0.005)\end{array}$ & $\begin{array}{l}-0.066^{* * *} \\
(0.005)\end{array}$ & & \\
\hline Foreign born came after 2004 & & & & & $\begin{array}{l}-0.074^{* * *} \\
(0.006)\end{array}$ & $\begin{array}{l}-0.074^{* * *} \\
(0.006)\end{array}$ \\
\hline Observations & 67,672 & 67,672 & 62,791 & 62,791 & 61,643 & 61,643 \\
\hline Sociodemographic characteristics & NO & YES & NO & YES & NO & YES \\
\hline Mean of dep. var. & 0.114 & 0.114 & 0.112 & 0.112 & 0.113 & 0.113 \\
\hline Std. dev. of dep. var. & 0.318 & 0.318 & 0.316 & 0.316 & 0.317 & 0.317 \\
\hline
\end{tabular}

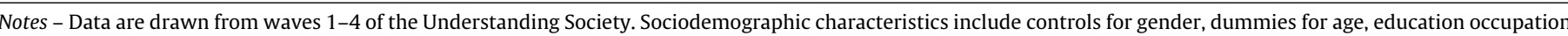
(1-digit), employment status, income, region, an index of rural status, and year fixed effects. Robust standard errors are reported in parentheses.

*** Significant at the $1 \%$ level.

Table A16

Immigrant-native differences in health care use (Understanding Society, 2009-2014).

\begin{tabular}{|c|c|c|c|c|c|c|}
\hline & (1) & (2) & $(3)$ & (4) & (5) & (6) \\
\hline \multicolumn{7}{|c|}{ Panel A: Inpatient days, waves 1-4 } \\
\hline Foreign born & $\begin{array}{l}-0.001 \\
(0.002)\end{array}$ & $\begin{array}{l}-0.001 \\
(0.002)\end{array}$ & & & & \\
\hline Foreign born came after 2000 & & & $\begin{array}{l}-0.010^{* * *} \\
(0.003)\end{array}$ & $\begin{array}{l}-0.010^{* * *} \\
(0.003)\end{array}$ & & \\
\hline Foreign born came after 2004 & & & & & $\begin{array}{l}-0.013^{* * *} \\
(0.003)\end{array}$ & $\begin{array}{l}-0.013^{* * *} \\
(0.003)\end{array}$ \\
\hline Observations & 67,672 & 67,672 & 62,791 & 62,791 & 61,643 & 61,643 \\
\hline Sociodemographic controls & NO & YES & NO & YES & NO & YES \\
\hline Mean of dep. var. & 0.0196 & 0.0196 & 0.0190 & 0.0190 & 0.0191 & 0.0191 \\
\hline \multicolumn{6}{|c|}{ Panel B: Hospital services use, wave 4} & 0.158 \\
\hline Foreign born & $\begin{array}{l}-0.002 \\
(0.015)\end{array}$ & $\begin{array}{l}-0.002 \\
(0.015)\end{array}$ & & & & \\
\hline Foreign born came after 2000 & & & $\begin{array}{l}-0.037^{* *} \\
(0.018)\end{array}$ & $\begin{array}{l}-0.037^{* *} \\
(0.018)\end{array}$ & & \\
\hline Foreign born came after 2004 & & & & & $\begin{array}{l}-0.051^{* *} \\
(0.020)\end{array}$ & $\begin{array}{l}-0.051^{* *} \\
(0.020)\end{array}$ \\
\hline Observations & 4551 & 4551 & 3178 & 3178 & 2816 & 2816 \\
\hline Sociodemographic controls & NO & YES & NO & YES & NO & YES \\
\hline Mean of dep. var. & 0.483 & 0.483 & 0.459 & 0.459 & 0.457 & 0.457 \\
\hline $\begin{array}{l}\text { Std. dev. of dep. var. } \\
\text { Panel C: Doctor services use, wa }\end{array}$ & 0.500 & 0.500 & 0.498 & 0.498 & 0.498 & 0.498 \\
\hline Foreign born & $\begin{array}{l}0.020^{*} \\
(0.011)\end{array}$ & $\begin{array}{l}0.020^{*} \\
(0.011)\end{array}$ & & & & \\
\hline Foreign born came after 2000 & & & $\begin{array}{l}-0.020 \\
(0.014)\end{array}$ & $\begin{array}{l}-0.020 \\
(0.014)\end{array}$ & & \\
\hline
\end{tabular}


Table A16 (Continued)

\begin{tabular}{|c|c|c|c|c|c|c|}
\hline & (1) & (2) & (3) & (4) & (5) & (6) \\
\hline Foreign born came after 2004 & & & & & $\begin{array}{l}-0.026 \\
(0.016)\end{array}$ & $\begin{array}{l}-0.026 \\
(0.016)\end{array}$ \\
\hline Observations & 4551 & 4551 & 3178 & 3178 & 2816 & 2816 \\
\hline Sociodemographic characteristics & NO & YES & NO & YES & NO & YES \\
\hline Mean of dep. var. & 0.846 & 0.846 & 0.821 & 0.821 & 0.821 & 0.821 \\
\hline Std. dev. of dep. var. & 0.361 & 0.361 & 0.383 & 0.383 & 0.384 & 0.384 \\
\hline
\end{tabular}

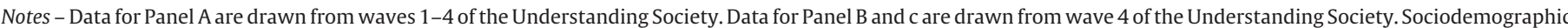

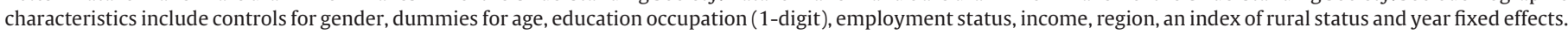
Robust standard errors are reported in parentheses.

* Significant at the $10 \%$ level.

** Significant at the 5\% level.

*** Significant at the $1 \%$ level.

Table A17

Immigrant-native differences in health care use (General Household Survey, 2000-2006).

\begin{tabular}{|c|c|c|c|c|c|c|}
\hline & (1) & $(2)$ & (3) & $(4)$ & $(5)$ & (6) \\
\hline \multicolumn{7}{|c|}{ Panel A: Consulted doctor last 2 weeks (exc.hosp) } \\
\hline Foreign born & $\begin{array}{l}0.007^{*} \\
(0.004)\end{array}$ & $\begin{array}{l}0.007^{*} \\
(0.004)\end{array}$ & & & & \\
\hline Foreign born came after 2000 & & & $\begin{array}{l}-0.049^{* * *} \\
(0.007)\end{array}$ & $\begin{array}{l}-0.028^{* * *} \\
(0.007)\end{array}$ & & \\
\hline Foreign born came after 2004 & & & & & $\begin{array}{l}-0.069^{* * *} \\
(0.012)\end{array}$ & $\begin{array}{l}-0.048^{* * *} \\
(0.012)\end{array}$ \\
\hline Observations & 137,273 & 137,273 & 128,494 & 128,494 & 127,121 & 127,121 \\
\hline Sociodemographic controls & NO & YES & NO & YES & NO & YES \\
\hline Mean of dep. var. & 0.153 & 0.153 & 0.152 & 0.152 & 0.152 & 0.152 \\
\hline Std. err. of dep. var. & 0.360 & 0.360 & 0.359 & 0.359 & 0.359 & 0.359 \\
\hline \multicolumn{7}{|c|}{ Panel B: NHS GP consultations last 2 weeks } \\
\hline Foreign born & $\begin{array}{l}0.004 \\
(0.005)\end{array}$ & $\begin{array}{l}0.006 \\
(0.005)\end{array}$ & & & & \\
\hline Foreign born came after 2000 & & & $\begin{array}{l}-0.067^{* * *} \\
(0.009)\end{array}$ & $\begin{array}{l}-0.044^{* * *} \\
(0.009)\end{array}$ & & \\
\hline Foreign born came after 2004 & & & & & $\begin{array}{l}-0.086^{* * *} \\
(0.013)\end{array}$ & $\begin{array}{l}-0.065^{* * *} \\
(0.014)\end{array}$ \\
\hline Observations & 137,273 & 137,273 & 128,494 & 128,494 & 127,121 & 127,121 \\
\hline Sociodemographic controls & NO & YES & NO & YES & NO & YES \\
\hline Mean of dep. var. & 0.168 & 0.168 & 0.167 & 0.167 & 0.167 & 0.167 \\
\hline Std. err. of dep. var. & 0.470 & 0.470 & 0.468 & 0.468 & 0.469 & 0.469 \\
\hline \multicolumn{7}{|l|}{ Panel C: NHS GP consultations last year } \\
\hline Foreign born & $\begin{array}{l}0.103 \\
(0.124)\end{array}$ & $\begin{array}{l}0.168 \\
(0.128)\end{array}$ & & & & \\
\hline Foreign born came after 2000 & & & $\begin{array}{l}-1.744^{* * *} \\
(0.225)\end{array}$ & $\begin{array}{l}-1.140^{* * *} \\
(0.230)\end{array}$ & & \\
\hline Foreign born came after 2004 & & & & & $\begin{array}{l}-2.228^{* * *} \\
(0.350)\end{array}$ & $\begin{array}{l}-1.682^{* * *} \\
(0.356)\end{array}$ \\
\hline Observations & 137,275 & 137,275 & 128,497 & 128,497 & 127,122 & 127,122 \\
\hline Sociodemographic controls & NO & YES & NO & YES & NO & YES \\
\hline Mean of dep. var. & 4.366 & 4.366 & 4.332 & 4.332 & 4.349 & 4.349 \\
\hline Std. err. of dep. var. & 12.22 & 12.22 & 12.18 & 12.18 & 12.20 & 12.20 \\
\hline \multicolumn{7}{|c|}{ Panel D: Hospital Outpatient Attend - last 3 months } \\
\hline Foreign born & $\begin{array}{l}-0.015^{* * *} \\
(0.003)\end{array}$ & $\begin{array}{l}-0.010^{* * *} \\
(0.004)\end{array}$ & & & & \\
\hline Foreign born came after 2000 & & & $\begin{array}{l}-0.050^{* * *} \\
(0.007)\end{array}$ & $\begin{array}{l}-0.019^{* * *} \\
(0.007)\end{array}$ & & \\
\hline Foreign born came after 2004 & & & & & $\begin{array}{l}-0.063^{* * *} \\
(0.012)\end{array}$ & $\begin{array}{l}-0.033^{* * *} \\
(0.012)\end{array}$ \\
\hline Observations & 137,287 & 137,287 & 128,506 & 128,506 & 127,132 & 127,132 \\
\hline Sociodemographic characteristics & NO & YES & NO & YES & NO & YES \\
\hline Mean of dep. var. & 0.144 & 0.144 & 0.145 & 0.145 & 0.145 & 0.145 \\
\hline Std. err. of dep. var. & 0.351 & 0.351 & 0.352 & 0.352 & 0.352 & 0.352 \\
\hline
\end{tabular}

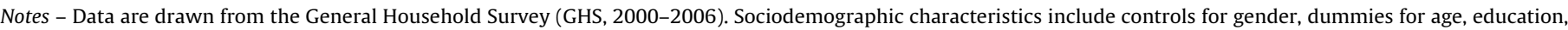
income, region and an index of rural status and an indicator for missing information on income.

* Significant at the $10 \%$ level.

*** Significant at the $1 \%$ level. 
Table A18

Health across less and more deprived areas in England (LFS, 2003-2012).

\begin{tabular}{|c|c|c|c|c|c|c|}
\hline Dependent variable: & $\begin{array}{l}(1) \\
\text { Any health issue } \\
\text { All }\end{array}$ & $\begin{array}{l}(2) \\
\text { Any health issue } \\
\text { All }\end{array}$ & $\begin{array}{l}\text { (3) } \\
\text { Any health issue } \\
\text { UK-born }\end{array}$ & $\begin{array}{l}(4) \\
\text { Any health issue } \\
\text { UK-born }\end{array}$ & $\begin{array}{l}\text { (5) } \\
\text { Any health issue } \\
\text { Foreign-born }\end{array}$ & $\begin{array}{l}(6) \\
\text { Any health issue } \\
\text { Foreign-born }\end{array}$ \\
\hline Highly deprived areas & $\begin{array}{l}0.016^{* * *} \\
(0.001)\end{array}$ & $\begin{array}{l}0.010^{* * *} \\
(0.002)\end{array}$ & $\begin{array}{l}0.021^{* * *} \\
(0.001)\end{array}$ & $\begin{array}{l}0.011^{* * * *} \\
(0.002)\end{array}$ & $\begin{array}{l}0.023^{* * *} \\
(0.002)\end{array}$ & $\begin{array}{l}0.015^{* *} \\
(0.006)\end{array}$ \\
\hline $\begin{array}{l}\text { Sociodemographic controls } \\
\text { Year F.E. } \\
\text { Local authority F.E. } \\
\text { Mean of dep.var. } \\
\text { Std. err. }\end{array}$ & $\begin{array}{l}\text { NO } \\
\text { YES } \\
\text { YES } \\
0.302 \\
(0.459)\end{array}$ & $\begin{array}{l}\text { YES } \\
\text { YES } \\
\text { YES } \\
0.319 \\
(0.466)\end{array}$ & $\begin{array}{l}\text { NO } \\
\text { YES } \\
\text { YES } \\
0.326 \\
(0.469)\end{array}$ & $\begin{array}{l}\text { YES } \\
\text { YES } \\
\text { YES } \\
0.329 \\
(0.470)\end{array}$ & $\begin{array}{l}\text { NO } \\
\text { YES } \\
\text { YES } \\
0.242 \\
(0.429)\end{array}$ & $\begin{array}{l}\text { YES } \\
\text { YES } \\
\text { YES } \\
0.244 \\
(0.429)\end{array}$ \\
\hline Observations & $1,596,291$ & $1,551,777$ & $1,392,313$ & $1,351,754$ & 203,841 & 199,886 \\
\hline
\end{tabular}

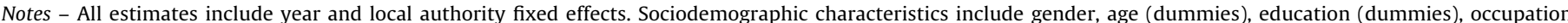
(1-digit, dummies). Standard errors in parentheses are clustered at the local authority level. Robust standard errors are reported in parentheses.

** Significant at the $5 \%$ level.

*** Significant at the $1 \%$ level.

Table A19

Asylum seekers and waiting times for outpatients, 2003-2012.

\begin{tabular}{|c|c|c|c|c|c|c|}
\hline & $\begin{array}{l}\text { (1) } \\
\text { OLS }\end{array}$ & $\begin{array}{l}\text { (2) } \\
\text { OLS }\end{array}$ & $\begin{array}{l}\text { (3) } \\
\text { OLS }\end{array}$ & $\begin{array}{l}\text { (4) } \\
\text { OLS }\end{array}$ & $\begin{array}{l}(5) \\
2 S L S\end{array}$ & $\begin{array}{l}(6) \\
2 S L S\end{array}$ \\
\hline Share of asylum seekers in a local authority & $\begin{array}{l}80.421^{* * *} \\
(9.077)\end{array}$ & $\begin{array}{l}24.499^{* * *} \\
(7.397)\end{array}$ & & & $\begin{array}{l}68.646^{* * *} \\
(12.180)\end{array}$ & $\begin{array}{l}3.985 \\
(13.322)\end{array}$ \\
\hline Share of asylum seekers in dispersal accommodation & & & $\begin{array}{l}76.776^{* * *} \\
(13.963)\end{array}$ & $\begin{array}{l}3.733 \\
(12.548)\end{array}$ & & \\
\hline PCT f.e. & YES & YES & YES & YES & YES & YES \\
\hline Year f.e. & NO & YES & NO & YES & NO & YES \\
\hline Observations & 293,382 & 293,382 & 293,382 & 293,382 & 293,382 & 293,382 \\
\hline First-stage $F$ & & & & & 1529 & 627.2 \\
\hline
\end{tabular}

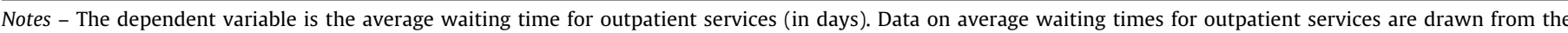

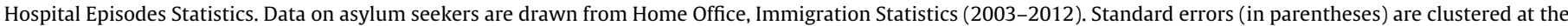
local authority level.

*** Significant at the $1 \%$ level.

Table A20

Immigration and waiting times, first stage.

\begin{tabular}{|c|c|c|c|}
\hline \multirow[b]{2}{*}{ Dependent variable: } & (1) & $(2)$ & (3) \\
\hline & \multicolumn{3}{|c|}{ Share of immigrants } \\
\hline IV & $\begin{array}{l}0.513^{* * *} \\
(0.111)\end{array}$ & $\begin{array}{l}0.575^{* * *} \\
(0.120)\end{array}$ & $\begin{array}{l}0.575^{* * *} \\
(0.120)\end{array}$ \\
\hline Year f.e. & YES & YES & YES \\
\hline PCT f.e. & YES & YES & YES \\
\hline LSOA time-varying characteristics & NO & YES & YES \\
\hline LSOA population & NO & NO & YES \\
\hline Observations & 258,458 & 258,458 & 258,458 \\
\hline First-stage $F$ & 17.11 & 16.07 & 16.05 \\
\hline$R^{2}$ & 0.974 & 0.975 & 0.975 \\
\hline
\end{tabular}

Notes - Data on immigrant distribution across Local Authorities are drawn from the UK Labor Force Survey. Time-varying LSOA characteristics include an Index of Deprivation (we use dummies for each decile of the index) and an indicator for rural status, the share of women, and the share of over 65 in the LSOA population. PCT time-varying characteristics include ratio of occupied hospital beds to population, number of GPs per capita, number of GP practice per capita, number of health consultants per capita, health expenditure per capita, incidence of most common diseases. Columns 3 and 6 include LSOA size. Standard errors are clustered at the local authority level.

*** Significant at the $1 \%$ level.

\section{Appendix B. Data sources}

UK Labour Force Survey (LFS, 2003-2012): The LFS is a quarterly survey of employment and labor markets in the UK. We use the special license version of the survey which includes local authority level information. Source: Office for National Statistics.

National Insurance Number (NINO) registration of overseas nationals (2002-2012): NINOs are used to record contributions and taxes of individuals. The NINO is also necessary for most benefit claims. Source: Department for Work and Pensions.

Asylum Seeker Statistics (2003-2012): This reports the number of asylum seekers in each local authority receiving Government support (Section 95). It includes asylum seekers in dispersal and non-dispersal accommodation. Source: Home Office.

Hospital Episode Statistics (HES, 2003-2012): It is a recordsbased system that covers all NHS trusts in England, including acute hospitals, primary care trusts and mental health trusts. Source: Health and Social Care Information Centre.

Understanding Society (US, 2009-2014): It is the largest panel survey in the world, supporting social and economic research. Its sample size is 40,000 households from around the UK. Source: Understanding Society project.

General Household Survey (GHS, 2002-2006): It is a multipurpose continuous survey carried out by the collecting information on a range of topics from people living in private households in Great Britain. Source: Office for National Statistics.

\section{References}

Altonji, J.G., Card, D., 1991. The effects of immigration on the labor market outcomes of less-skilled natives. In: Immigration, Trade and the Labor Market. University of Chicago Press, pp. 201-234.

Appleby, J., 2012. Public Satisfaction with the NHS and Its Services. Headlines from the British Social Attitudes Survey. The King's Fund, London.

Appleby, J., Thompson, J., Jabbal, J., 2014. How is the NHS Performing? The King's Fund Quarterly Monitoring Report.

Aydemir, A.B., Borjas, G.J., 2011. Attenuation bias in measuring the wage impact of immigration. J. Labor Econ. 29 (1), 69-112. 
Barr, B., Bambra, C., Whitehead, M., 2014. The impact of NHS resource allocation policy on health inequalities in England 2001-11: longitudinal ecological study. BMJ 348, g3231.

Beckert, W., Christensen, M., Collyer, K., 2012. Choice of NHS-funded hospital services in England. Econ. J. 122 (560), 400-417.

Bell, B., Fasani, F., Machin, S., 2013. Crime and immigration: evidence from large immigrant waves. Rev. Econ. Stat. 21 (3), 1278-1290.

Blinder, S., 2012. UK Public Opinion Toward Immigration: Overall Attitudes and Level of Concern. Centre on Migration, Policy and Society Briefing Paper, Available at http://www.migrationobservatory.ox.ac.uk/sites/files/migobs/ Public\%200pinion-Overall\%20Attitudes\%20and\%20Level\%20of\%20Concern.pdf.

Borjas, G.J., 2003. The labor demand curve is downward sloping: reexamining the impact of immigration on the labor market. Q. J. Econ. 118 (4), 1335-1374.

Borjas, G.J., 2006. Native internal migration and the labor market impact of immigration. J. Hum. Resour. 41 (2), 221-258.

Borjas, G.J., Freeman, R.B., Katz, L.F., 1996. Searching for the effect of immigration on the labor market. Am. Econ. Rev. 86 (2), 246-251.

Card, D., 2001. Immigrant inflows, native outflows, and the local labor market impacts of higher immigration. J. Labor Econ. 19 (1), 22-64.

Castelli, A., Dawson, D., Gravelle, H., Jacobs, R., Kind, P., Loveridge, P., Martin, S., O’Mahony, M., Stevens, P.A., Stokes, L., et al., 2007. A new approach to measuring health system output and productivity. Natl. Inst. Econ. Rev. 200 (1), 105-117.

Chiswick, B.R., Lee, Y.L., Miller, P.W., 2008. Immigrant selection system and immigrant health. Contemp. Econ. Policy 26 (4), 1074-3529.

Cooper, Z.N., McGuire, A., Jones, S., Le Grand, J., 2009. Equity, waiting times, and NHS reforms: retrospective study. BMJ, 339.

Cullis, J.G., Jones, P.R., Propper, C., 2000. Waiting lists and medical treatment: analysis and policies. Handb. Health Econ. 1, 1201-1249.

Dixon, A., Robertson, R., 2011. Patient Choice of Hospital.

Dustmann, C., Frattini, T., 2014. The fiscal effects of immigration to the UK. Econ. J. 124 (580), F593-F643.

Dustmann, C., Frattini, T., Halls, C., 2010. Assessing the fiscal costs and benefits of A8 migration to the UK. Fiscal Stud. 31 (1), 1-41.

Dustmann, C., Frattini, T., Preston, I.P., 2013. The effect of immigration along the distribution of wages. Rev. Econ. Stud. 80 (1), 145-173.

Foged, M., Peri, G., 2016. Immigrants' effect on native workers: new analysis on longitudinal data. Am. Econ. J.: Appl. Econ. 8 (2), 1-34.

Gaynor, M., Laudicella, M., Propper, C., 2012a. Can governments do it better? Merger mania and hospital outcomes in the English NHS. J. Health Econ. 31 (3), 528-543.

Gaynor, M., Propper, C., Seiler, S., 2012. Free to choose? Reform and demand response in the English National Health Service. NBER Working Paper (18574)

Giuntella, O., 2013. Why Does the Health of Immigrants Deteriorate? Evidence from Birth Records. IZA Discussion Paper 7588.

Giuntella, O., Mazzonna, F., 2015. Do immigrants improve the health of natives? J. Health Econ. 43, 140-153.

Gutacker, N., Siciliani, L., Moscelli, G., Gravelle, H., 2015. Do Patients Choose Hospitals That Improve Their Health? CHE Research Paper 111.

Ham, C., 2014. Reforming the NHS from Within. Beyond Hierarchy, Inspection and Markets. Kings Fund, London.

Hatton, T.J., Tani, M., 2005. Immigration and inter-regional mobility in the UK, 1982-2000. Econ. J. 115 (507), F342-F358.

Jasso, G., Massey, D.S., Rosenzweig, M.R., Smith, J.P., 2004. Immigrant Health: Selectivity and Acculturation. The Institute for Fiscal Studies Working Paper 4 (23)., pp. 1-46.
Kennedy, S., Kidd, M.P., McDonald, J.T., Biddle, N., 2014. The healthy immigrant effect: patterns and evidence from four countries. J. Int. Migr. Integr. 16 (2) 317-332.

Laudicella, M., Siciliani, L., Cookson, R., 2012. Waiting times and socioeconomic status: evidence from England. Soc. Sci. Med. 74 (9), 1331-1341.

Lindsay, C.M., Feigenbaum, B., 1984. Rationing by waiting lists. Am. Econ. Rev. 75 (3), 404-417.

Lucchino, P., Rosazza-Bondibene, C., Portes, J., 2012. Examining the Relationship Between Immigration and Unemployment Using National Insurance Number Registration Data. NIESR Discussion Paper No. 386.

Martin, S., Rice, N., Jacobs, R., Smith, P., 2007. The market for elective surgery: joint estimation of supply and demand. J. Health Econ. 26 (2), 263-285.

Norman, P., Boyle, P., Rees, P., 2005. Selective migration, health and deprivation: a longitudinal analysis. Soc. Sci. Med. 60 (12), 2755-2771.

Orrenius, P.M., Zavodny, M., 2015. Does immigration affect whether US natives major in science and engineering? J. Labor Econ. 33 (S1), S79-S108.

Palloni, A., Morenoff, J.D., 2001. Interpreting the paradoxical in the Hispanic paradox. Ann. N. Y. Acad. Sci. 954 (1), 140-174.

Propper, C., 1995. The disutility of time spent on the United K ingdom's National Health Service waiting lists. J. Hum. Resour., 677-700.

Propper, C., Burgess, S., Gossage, D., 2008a. Competition and quality: evidence from the NHS internal market 1991-9. Econ. J. 118 (525), 138-170.

Propper, C., Damiani, M., Leckie, G., Dixon, J., 2007. Impact of patients' socioeconomic status on the distance travelled for hospital admission in the English National Health Service. J. Health Serv. Res. Policy 12 (3), 153-159.

Propper, C., Sutton, M., Whitnall, C., Windmeijer, F., 2008. Did 'targets and terror' reduce waiting times in England for hospital care? BE J. Econ. Anal. Policy 8 (2)

Rienzo, C., Vargas-Silva, C., 2012. Migrants in the UK: An Overview. Migration Observatory Briefing, COMPAS. University of Oxford, Oxford.

Ruhm, C.J., 2000. Are recessions good for your health? Q. J. Econ. 115 (2), 617-650.

Sá, F., 2015. Immigration and house prices in the UK. Econ. J. 125 (587), 1393-1424

Shutes, I., 2011. Social Care for Older People and Demand for Migrant Workers. The Migration Observatory. Centre on Migration, Policy and Society, University of Oxford.

Siciliani, L., Iversen, T., 2012. Waiting times and waiting lists. The Elgar Companion to Health Economics, 259

Silvester, K., Lendon, R., Bevan, H., Steyn, R., Walley, P., 2004. Reducing waiting times in the NHS: is lack of capacity the problem? Clin. Manag. 12 (3), 105-111

Sitzia, J., Wood, N., 1997. Patient satisfaction: a review of issues and concepts. Soc. Sci. Med. 45 (12), 1829-1843.

Steventon, A., Bardsley, M., 2011. Use of secondary care in England by international immigrants. J. Health Serv. Res. Policy 16 (2), 90-94.

Wadsworth, J., 2013. Mustn't grumble: immigration, health and health service use in the UK and Germany. Fiscal Stud. 34 (1), 55-82.

Windmeijer, F., Gravelle, H., Hoonhout, P., 2005. Waiting lists, waiting times and admissions: an empirical analysis at hospital and general practice level. Health Econ. 14 (9), 971-985.

Wooldridge, M., 2002. Econometric Analysis of Cross Section and Panel Data. The MIT Press, Cambridge, MA.

Yar, M., Dix, D., Bajekal, M., 2006. Socio-demographic characteristics of the healthcare workforce in England and Wales - results from the 2001 census. Health Stat. Q. 32, 44-55. 